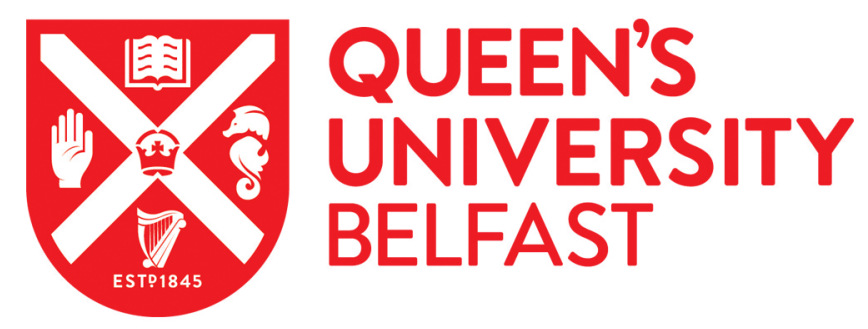

\title{
Extrusion-based additive manufacturing with cement-based materials - Production steps, processes, and their underlying physics: A review
}

Mechtcherine, V., Bos, F. P., Perrot, A., Leal da Silva, W. R., Nerella, V. N., Fataei, S., Wolfs, R. J., Sonebi, M., \& Roussel, N. (2020). Extrusion-based additive manufacturing with cement-based materials - Production steps, processes, and their underlying physics: A review. Cement and Concrete Research, 132, [106037]. https://doi.org/10.1016/j.cemconres.2020.106037

Published in:

Cement and Concrete Research

Document Version:

Peer reviewed version

Queen's University Belfast - Research Portal:

Link to publication record in Queen's University Belfast Research Portal

\section{Publisher rights}

Copyright 2020 Elsevier.

This manuscript is distributed under a Creative Commons Attribution-NonCommercial-NoDerivs License

(https://creativecommons.org/licenses/by-nc-nd/4.0/), which permits distribution and reproduction for non-commercial purposes, provided the author and source are cited.

\section{General rights}

Copyright for the publications made accessible via the Queen's University Belfast Research Portal is retained by the author(s) and / or other copyright owners and it is a condition of accessing these publications that users recognise and abide by the legal requirements associated with these rights.

Take down policy

The Research Portal is Queen's institutional repository that provides access to Queen's research output. Every effort has been made to ensure that content in the Research Portal does not infringe any person's rights, or applicable UK laws. If you discover content in the Research Portal that you believe breaches copyright or violates any law, please contact openaccess@qub.ac.uk. 


\title{
1 Extrusion-based additive manufacturing with cement-based materials - Pro-
} duction steps, processes, and their underlying physics: A review

\author{
V. Mechtcherine ${ }^{1}$, F. P. Bos $^{2}$, A. Perrot ${ }^{3}$, W. R. Leal da Silva ${ }^{4}$, V.N. Nerella ${ }^{1}$, S. Fataei ${ }^{1}$, R. J. \\ M. Wolfs ${ }^{2}$, M. Sonebi ${ }^{5}$, N. Roussel ${ }^{6}$ \\ ${ }^{1}$ Institute of Construction Materials, TU Dresden, 01062 Dresden, Germany \\ ${ }^{2}$ Department of the Built Environment, Eindhoven University of Technology, Netherlands \\ ${ }^{3}$ Univ. Bretagne-Sud, UMR CNRS 6027, IRDL, F-56100 Lorient, France \\ ${ }^{4}$ The Danish Technological Institute, Taastrup, Denmark \\ ${ }^{5}$ School of Natural and Built Environment, Queen's University Belfast, Belfast BT9 5AG, \\ Northern Ireland, UK \\ ${ }^{6}$ Laboratoire NAVIER, Ecole des Ponts ParisTech, 6 / 8 avenue Blaise Pascal, Champs sur \\ Marne, F-77455 Marne la Vallee CEDEX 2, Paris, France
}

\begin{abstract}
This article offers a comprehensive overview of the underlying physics relevant to an understanding of materials processing during the various production steps in extrusion-based 3D Concrete Printing (3DCP). Understanding the physics governing the processes is an important step toward the purposeful design and optimization of 3DCP systems as well as their efficient and robust process control. For some processes, analytical formulas based on the relevant physics have already enabled reasonable predictions with respect to material flow behavior and buildability, especially in the case of relatively simple geometries.

The existing research in the field was systematically compiled by the authors in the framework of the activities of the RILEM Technical Committee 276 "Digital fabrication with cementbased materials". However, further research is needed to develop reliable tools for the quantitative analysis of the entire process chain. To achieve this, experimental efforts for the characterization of material properties need to go hand in hand with comprehensive numerical simulation.
\end{abstract}

Keywords: Concrete technology; additive manufacturing; 3D-printing; extrusion; production; underlying physics

\section{Introduction}

Digitalization and automation in construction bring great potential in respect of increases in productivity, in creating more attractive jobs, and in compensating for shortages of skilled labor $[1,2]$. Large-scale Additive Manufacturing (AM) with cement-based materials, commonly referred to as 3D Concrete Printing (3DCP), belongs to the most promising new concrete technologies for implementing digital data from the planning phase and ultimately to actual automated production in factories and on construction sites [3, 4]. Not only can 3DCP facilitate and quicken production processes considerably, it can also make it technically and economically feasible to realize topologically optimized, geometrically complex structural elements designed according to the principle form follows force and also enable the integration of various functionalities. Such topological optimization allows for elegant, material-minimized, and resourcesaving structures $[2,5]$.

Over the last decade various 3DCP approaches have been developed, and a number of realscale pilot projects have been successfully completed; see e.g. [6, 7]. According to the RILEM process classification framework for Digital Fabrication with Concrete (DFC) technologies [8], the existing approaches of AM with cement-based materials can be subdivided into different 
groups, of which material extrusion, particle-bed binding, and material jetting are three that have been demonstrated at scale. While these groups and individual approaches within the groups differ considerably with respect to their respective material concepts, equipment, and production steps, all of them base themselves on sound interaction between material and machine along the processing chain. Hence, mastering material-machine interactions is a prerequisite for efficient and robust processes, and for their optimization and control. Such mastering is only possible if the underlying physics of individual 3DCP processes are well understood and purposefully applied.

In this light and in understanding the importance of the topic with respect to successful implementation of DFC technologies into the practice of construction, the authors dedicated considerable time and effort to the systematic analysis of the physical background of various DFC technologies and their individual processing steps. Initiated as an activity of the RILEM Technical Committee 276 "Digital fabrication with cement-based materials", an important outcome of this work is the article at hand, which focuses on the first group of AM approaches - namely, DFC technologies whose basis is material extrusion. The choice of this DFC group was straightforward since extrusion-based 3DCP approaches dominate the field both in research and first applications worldwide. Thus, at present material extrusion seems a clear favorite with respect to both the level of overall technological readiness and economic viability [4, 9].

The goal of this contribution is to bring together in orderly fashion the relevant knowledge in physics needed to understand and to shape purposefully the relevant processes belonging to extrusion-based 3DCP. In doing so, first, the existing approaches of this DFC group are subdivided into three categories according to the respective major concepts of material handling. Second, the main production steps common to all extrusion-based approaches are defined. Next, the processes and underlying physics relevant to individual production steps are specified for each approach category. This is all laid out in Section 2 while the subsequent sections focus on the main processes, i.e., their physics, their corresponding key physical properties, and their evolution over time. Given the wide spectrum of the relevant processes and their complexity, the authors have aimed at providing a comprehensive overview of crucial aspects as a basis for a general understanding of the technology in the first place rather than trying to deliver the details on every process and its underlying physics. However, numerous references to important sources in the literature should help in finding additional information easily. To make the process and physical parameters "tangible" while providing some rough guidance with respect to relevant quantitative information, the ranges of absolute values are given as first estimates for the reader's consideration whenever it is possible and meaningful. Finally, attention is paid to research needs, of which a great many remain.

\section{Processing steps and their underlying physics}

The additive manufacturing approaches of material deposition by extrusion can be subdivided into three categories: i) extrusion of stiff material, similar to conventional extrusion, ii) extrusion of flowable material with or without adding admixture(s) in the printhead, and iii) extrusion of material using additional energy input, e.g. vibration, which facilitates the delivery and deposition of stiff mixtures. The ideal case of the first category is the "infinite brick" extrusion regime, where the filament and nozzle cross-sections are equal; see Figure 1a. In the second category the ideal case is free flow deposition, where the material flows freely until the stress induced by gravity equals the yield stress of the printable material; see [10] and Figure 1c. In the context of additive manufacturing with concrete, most extrusion flows are located somewhere between these two asymptotic deposition approaches; see Figure 1b. Note that while two asymptotic cases can be mathematically modeled as described in the next sections, the prediction of more realistic final shapes for real printable, cement-based materials is not straightfor- 
ward due to several mechanisms and boundaries involved. These mechanisms/boundaries include solicitation gradient, shear-induced particle migration, non-uniform structural build-up, complex nozzle geometry, and so on. In such cases adequate multi-physical, numerical tools would be required to describe the extrusion/deposition process fully. Analytical formulas can, however, still provide reasonable estimations. Finally, the third manufacturing approach, the extrusion of material using additional energy input, has been as yet rarely applied.

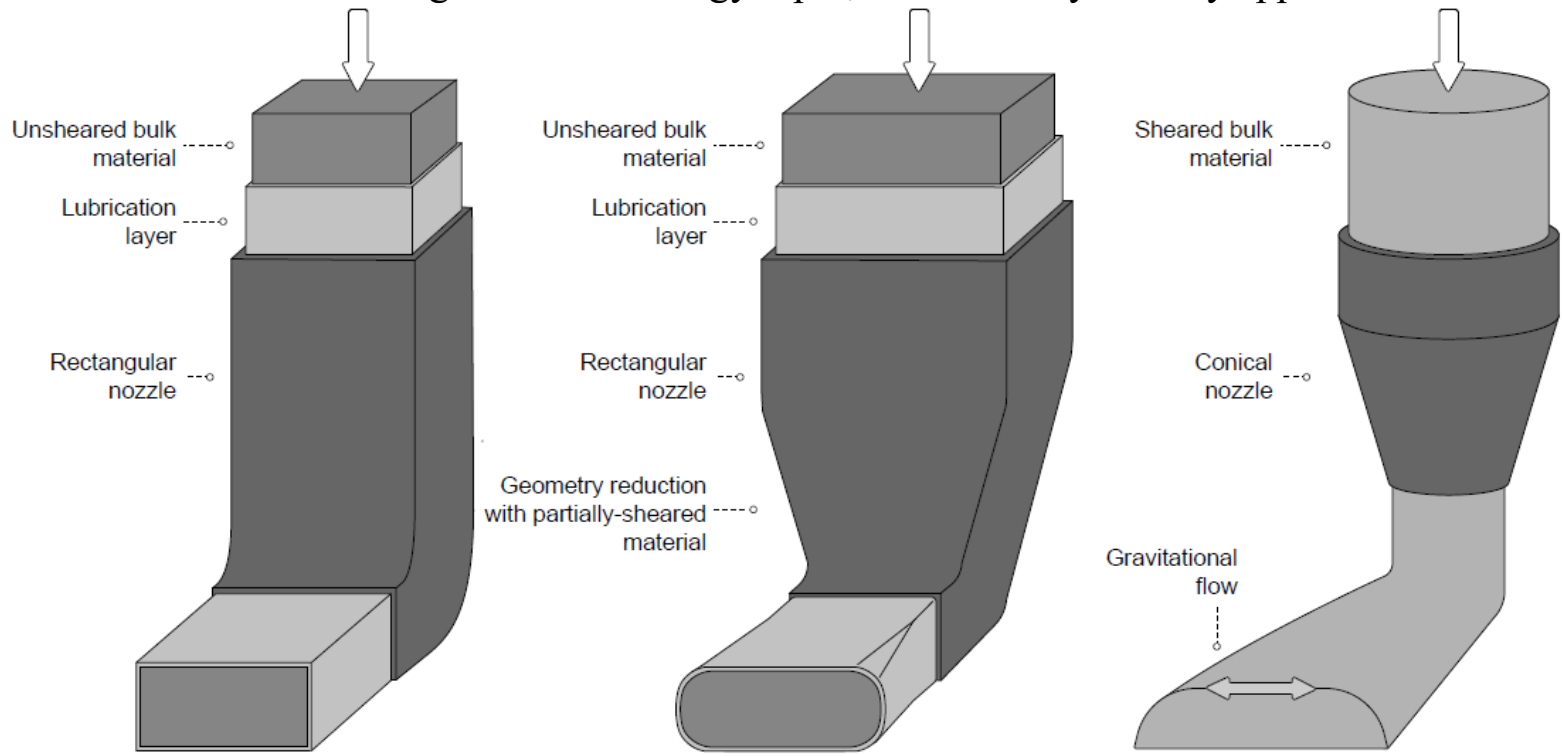

Figure 1. Two asymptotic regimes of material deposition by extrusion: a) extrusion of a very stiff material (so-called infinite brick strategy) and c) extrusion of very flowable material that spreads out after deposition (adapted from [10]); regime b) shows a more realistic case of extrusion of sufficiently stiff material by means of a nozzle with a geometric reduction.

In general the major processing steps in these manufacturing approaches are similar since they all include: 1) transportation of build material to the printhead, 2) printhead process/extrusion by the printhead, 3) deposition of build material, accompanied by its deformation, and 4) depositions of further layers, accompanied by loading earlier deposited upper layer(s) by selfweight and process-induced forces, related deformation of build material after deposition followed by further deformation due to early-age shrinkage, early-age creep, and thermal dilation.

Note that a technical discussion of the initial processing step, namely "concrete mixing" is beyond the scope of this publication. Thus, the first step in each presented approach is seen as "transportation". However, mixing in the printhead to disperse chemical admixtures such as hydration-accelerating agents is addressed here as a part of the printhead process. Table 1 lists three manufacturing approaches of selective material deposition by extrusion and four processing steps. The underlying physical processes for each processing step for a given fabrication approach are listed in Table 1 as well. These underlying physical processes, such as gravitational flow, pumping, i.e., pressure-induced flow in a pipe, or extrusion or pressure-induced flow through a section contraction, are presented and discussed in the following sections. However, early-age shrinkage, early-age creep and thermal dilation of the material after deposition are not covered in this article since they 1) do not represent a production step as such, b) are not considered to be different to conventional concrete construction from the physical point of view. 
131 Table 1. Production steps, related processes and underlying physics relevant to three different 132 approaches within the extrusion-based additive manufacturing with cement-based materials.

\begin{tabular}{|c|c|c|c|}
\hline \multirow[b]{2}{*}{ Production step } & \multicolumn{3}{|c|}{ Extrusion-based manufacturing approach } \\
\hline & $\begin{array}{c}\text { Extrusion of stiff mate- } \\
\text { rial }\end{array}$ & $\begin{array}{c}\text { Extrusion of flowable mate- } \\
\text { rial with or without disper- } \\
\text { sion of admixture(s) in the } \\
\text { printhead }\end{array}$ & $\begin{array}{l}\text { Extrusion of material using } \\
\text { additional energy input }\end{array}$ \\
\hline $\begin{array}{l}\text { Transportation of build } \\
\text { material (also primary } \\
\text { motivation) }\end{array}$ & $\begin{array}{l}\text { Pumping (over short } \\
\text { distances) or gravita- } \\
\text { tional flow with or } \\
\text { without energy input }\end{array}$ & Pumping & $\begin{array}{l}\text { Pumping or gravitational } \\
\text { flow with or without energy } \\
\text { input }\end{array}$ \\
\hline Printhead process & $\begin{array}{l}\text { Extrusion using pri- } \\
\text { mary motivation } \\
\text { (pumping), ram extru- } \\
\text { sion, or screw extrusion }\end{array}$ & $\begin{array}{c}\text { Extrusion using primary } \\
\text { motivation, ram extrusion, } \\
\text { or screw extrusion; optional } \\
\text { dispersion of admixture by } \\
\text { high-energy mixing }\end{array}$ & $\begin{array}{c}\text { Screw extrusion or gravita- } \\
\text { tional flow supported by vi- } \\
\text { bration }\end{array}$ \\
\hline $\begin{array}{l}\text { Deformation of build ma- } \\
\text { terial during deposition }\end{array}$ & \multicolumn{2}{|c|}{ Gravitational flow, viscoelastic-plastic deformations } & $\begin{array}{c}\text { Gravitational flow and com- } \\
\text { paction supported by vibra- } \\
\text { tion, elastic deformations }\end{array}$ \\
\hline $\begin{array}{l}\text { Behavior of build material } \\
\text { after deposition }\end{array}$ & \multicolumn{3}{|c|}{$\begin{array}{l}\text { Deformations due to self-weight and kinetic energy of deposition; } \\
\text { additionally: early-age shrinkage, early-age creep, thermal dilation }\end{array}$} \\
\hline
\end{tabular}

134

135

136

137

138

139

140

141

142

143

144

145

146

147

148

149

150

151

152

For the sake of clarity one of the approaches is depicted in Figure 2, which illustrates the processing steps belonging to the extrusion of flowable materials without addition of admixture in the printhead.

Generally, the behavior of fresh cementitious materials can be considered as visco-plastic. This means that, similar to solids, they do not flow until a given critical shear stress, i.e. yield stress $\tau_{c}$, is exceeded and, similar to a liquid, they flow when subjected to shear stresses greater than $\tau_{c}[11,12]$. Depending on the processing step during additive fabrication, either solid or fluid behavior is involved, e.g. during the conveying and feeding processes the material flows inside the transportation system and printhead, i.e. fluid behavior, while after deposition the material has to remain static (i.e. solid behavior, viscoelastic-plastic) [10].

Note that cement-based materials are heterogeneous, and this can have a pronounced effect on their flow behavior in specific cases. For example, in the case of pumping, shear-induced particle migration creates a lubrication layer that greatly influences the flow of the material [13]. As a result, neither the velocity profile nor the flow rate can be accurately predicted based on viscosity and yield stress of the bulk material. The formation of a lubrication layer may occur also during the extrusion process; see Figure 1a. 


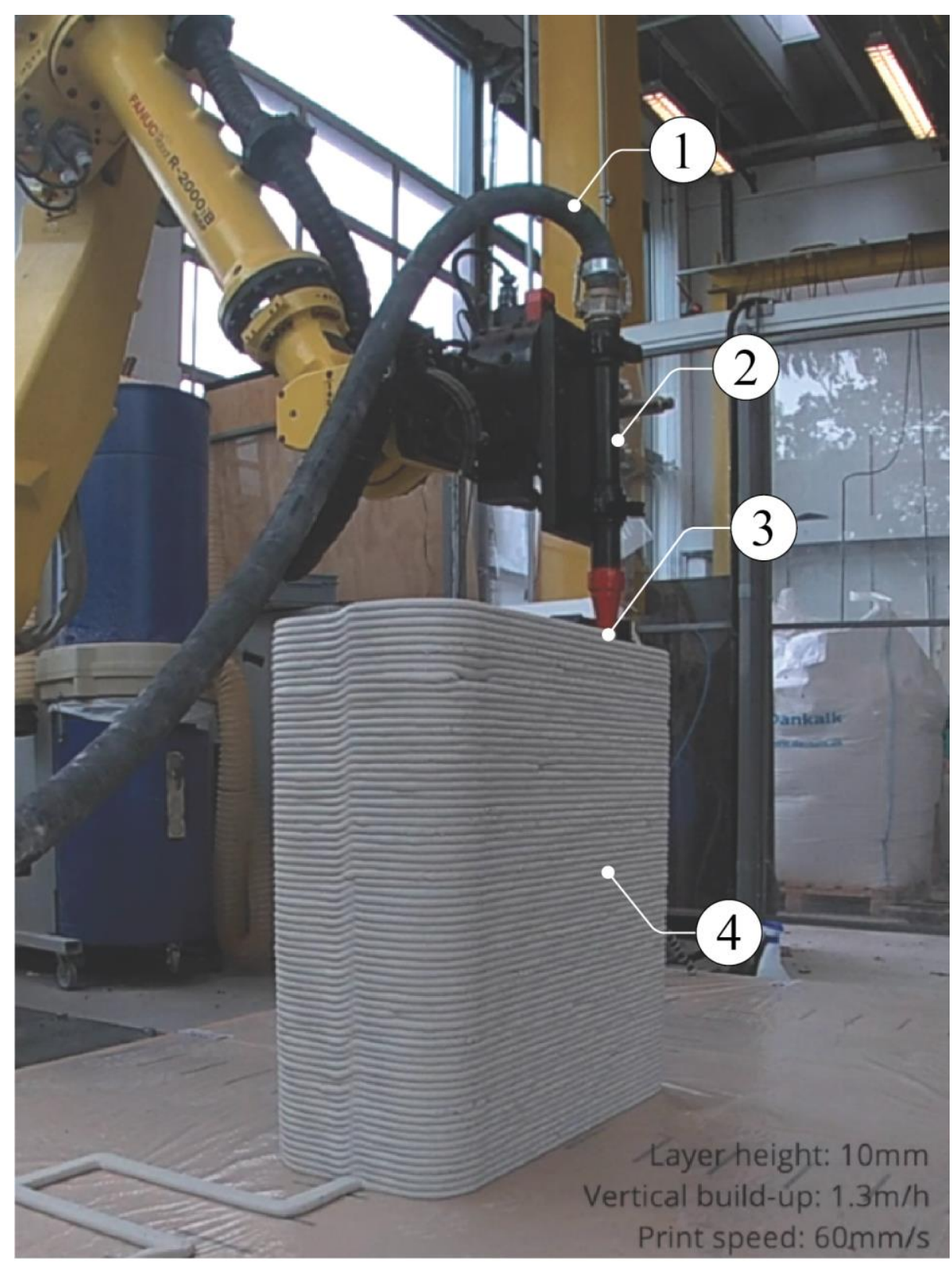

1. Transportation of build material - pumping

2. Printhead process - extrusion using primary motivation

3. Deformation of the build material during deposition - gravitational flow, viscoelastic-plastic deformations

4. Behavior of build material after deposition - deformations due to self-weight and kinetic energy from deposition; early-age shrinkage, early-age creep, thermal dilation

Figure 2. Processing steps in the extrusion of flowable materials.

\section{Gravitational flow}

157 During the 3D concrete printing process gravity plays a role in the transport of the material,

158 particularly between mixing and placement in a pumping or extrusion system. The gravity159 induced flow of material from a hopper to the pump is one of the printing steps that can be 160 studied by analogy to the discharge flows of the March cone, for example.

161 After deposition, there is "competition" between, the force of gravity and the material strength, 162 in rheological terms yield stress. This competition can be described by a dimensionless number, 163 i.e. the ratio of the gravity-induced stress $\rho g h$ over the material yield stress $\tau_{c}$, thus $\rho g h / \tau_{c}$, 
where $\rho$ is the material density, $\mathrm{g}$ is the acceleration of gravity, and $\mathrm{h}$ is the height of the deposited layer. Note that the balance between gravitationally induced stresses and the yield stress can be studied using the slump/spread flow theory developed by Roussel and Coussot [14]; see also Perrot et al. [15].

In the literature related to extrusion-based 3D printing process using cementitious materials, a wide range of material yield stress has been reported. Depending on the dimensionless number $\rho g h / \tau_{c}$ and the geometry of the nozzle's cross section, the final section of the material layer can vary from rectangular to semi-ellipsoidal, cf. [10]. Figure 1a shows a high yield stress of over $500 \mathrm{~Pa}$ for a cement-based material that keeps its shape after being deposited pursuant to the infinite brick strategy, while Figure 1c shows a filament of fluid cement-based material that spreads out after deposition with a yield stress of less than $100 \mathrm{~Pa}$. It is important to note here that for the case of printable cementitious materials with yield stress in the order of magnitude between hundred and thousands of $\mathrm{Pa}$ at the nozzle exit, the effect of the surface tension on the final shape of the layer can be neglected [10].

In the case where the yield stress of the material is greater than the stress induced by gravity, the layer of cementitious material will not be deformed after deposition. This scenario applies if the material is placed gently and relatively slowly; otherwise additional effects need to be considered. As proposed by Roussel and Coussot [14], this ideal case can be described using a purely elongational plastic model wherein the critical height of a stable layer reads $h_{\text {stable }}=$ $\sqrt{3} \tau_{c} / \rho g$ where $\sqrt{3} \tau_{c}$ is the elongational yield stress of the cementitious materials conditioned on their following von Mises plasticity criterion $[10,14,15,16]$. In other words, to enable cementitious materials to keep their shape after deposition, the target yield stress value should be at least around 13 Pa per millimeter of layer thickness (for $\rho$ of $2200 \mathrm{~kg} / \mathrm{m}^{3}$ ). Note that the plasticity criterion and its time dependency are still an open research question, especially for stiff mixtures, which can exhibit pressure-dependent behavior [17, 18].

If gravitational force overcomes the material elongational strength at the layer bottom, the material will deform until an equilibrium between yield stress and gravity-induced stress is reached. As a result, the layer being deposited will deform and spread on the previously printed layer. The limiting case of this type of behavior for a low yield-stress value tends to the case of shear flow on a horizontal plate. In this shear flow regime the final height of the layer should be equal to $h$ in $\rho g h$ [14]. In many 3D printing applications the actual filament deformation behavior ranges somewhere between the pure shear flow regime and the infinite brick, no-flow regime; thus, the final shape of the layer will depend on its material yield stress, on the crosssection of the nozzle opening, and on the gap between nozzle and printed layers, and this should be studied on a case-by-case basis. In this context, numerical analysis using e.g. Computation Fluid Dynamics (CFD) approaches can be instrumental in understanding material behavior better under specific boundary conditions and, prospectively, in predicting this behavior.

The effect of the gap between nozzle and deposition area on the shape of the deposited layer can also be important because tensile forces, i.e. in under-extrusion, where the material flow rate is lower than $S_{\text {nozzle }} \cdot V$, where $S_{\text {nozzle }}$ is the nozzle section and V the nozzle velocity, or compression forces in over-extrusion, where flow rate is higher than $S_{\text {nozzle }} \cdot V$, can be induced by the material leaving the nozzle; see Figure 3. These effects could lead to surface cracking, layer bending, or even coiling. These effects should be studied in some depth in order to allow for full control of layer geometry during printing.

Some extrusion-based, selective material deposition methods [19] purposefully establish a direct interaction between the nozzle and the extruded material: The nozzle presses the exiting material, forcing the layer to have a thickness equal to the gap between the nozzle and the layer 
below; it is assumed that the layer below is stiff enough to sustain this additional pressure without considerable deformation. This strategy has the advantage of eliminating uncertainty in the final height of the printed structures since the final printed structure height will only depend on the nozzle toolpath. While improving the overall geometry control of the printing process, the direct interaction of the nozzle and the deposited material induces additional pressure on the underlying layers at the level of the nozzle and can contribute to cracking or even to collapse of the printed element. Note that to date the tensile behavior of fresh, cement-based materials has not been extensively studied. One can mention the tensile strength measurement carried out by Mettler et al. [18] and Lo Monte et al. [20]. Nonetheless, a consistent explanation of the cracks' formation and the definition of mix-design solutions to prevent it, e.g. by adding fiber or polymer, are still open questions requiring extensive research.

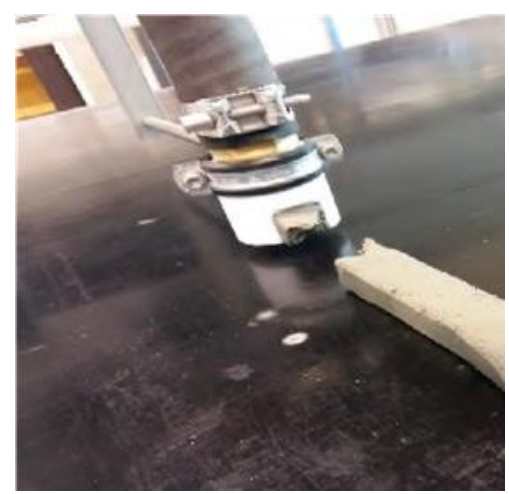

a)

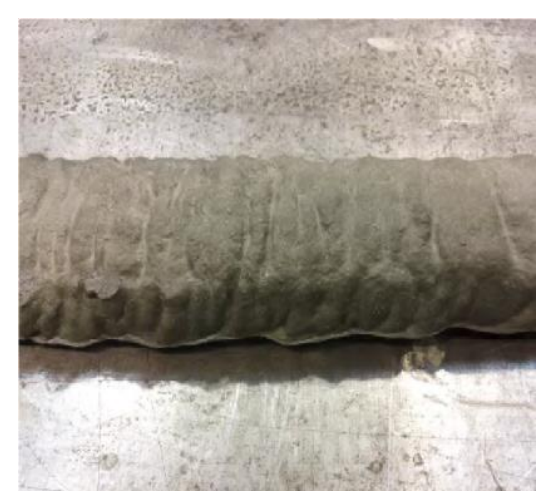

b)

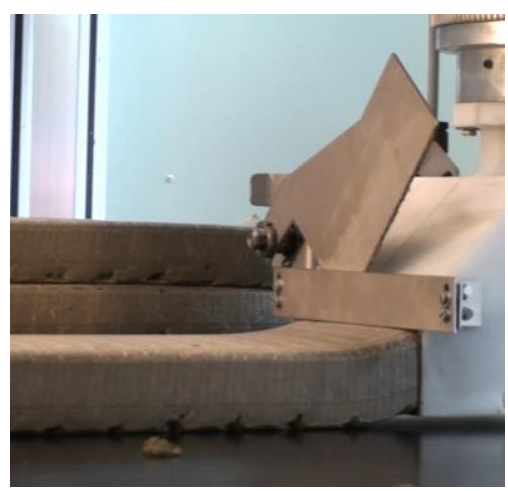

c)

Figure 3. Challenges in extruding concrete or mortar: a) extrusion rate is too low compared to the nozzle velocity leading to discontinuous layers [21], b) extrusion rate is too fast compared to the nozzle velocity leading to "buckled" layers [21], c) "tearing" of extruded layers due to the overly high yield stress of the printed material; adapted from [22].

\section{Pumping and extrusion}

\subsection{Pumping}

Pumping is often used in transporting mixed concrete to the printhead or nozzle. It is performed by pushing material through a hose with the help of positive-displacement piston pumps or progressive cavity pumps, the latter is so far the most widely implemented means in extrusionbased additive fabrication. While the pumping process as such is similar to ram extrusion, there are some distinctions worth addressing: it usually covers considerably longer distances and results in higher material discharge rates. Furthermore, ram extrusion usually implies compaction and shaping of the material by the nozzle narrowing towards its opening. Concrete pumpability as characterized by pressure losses depends primarily on the plastic viscosity. However, the influence of yield stress increases with increasing $\tau_{0} / \mu$ [23]. Calculations using the Buckingham-Reiner equation for laminar flow of a Bingham fluid through a pipe overestimate the pumping pressure for a given flow rate by up to 5 times $[13,24,25]$. This is a consequence of the formation of a lubricating layer (LL) at the inner walls of the pipeline due to shear-induced particle migration (SIPM). The yield stress and plastic viscosity of the LL are generally about one fifth and one fifteenth of the corresponding values of the bulk material, respectively [24]. The shear stress, shear rate, and velocity profiles of concrete during pumping are presented in Figure 4. 


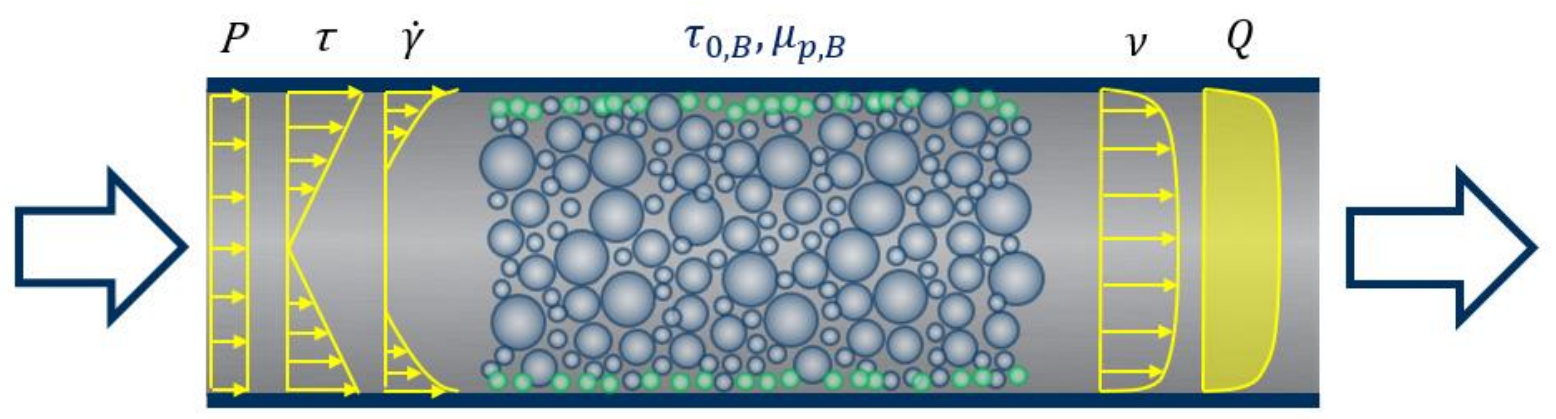

$$
\tau_{0, L L}, \mu_{p, L L}, e_{L L}
$$

Figure 4. Pressure $\mathrm{P}$, shear stress $\tau$, shear rate $\dot{\gamma}$, velocity $v$ and flowrate $\mathrm{Q}$ profiles of a concrete flow inside a pumping pipeline. The yield stress and plastic viscosity of concrete are $\tau_{0, B}$ and $\mu_{p, B}$, whereas the yield stress, plastic viscosity and thickness of the lubricating layer are $\tau_{0, L L}$, $\mu_{p, L L}$ and $e_{L L}$, adapted from [26].

Shear rate and shear stress are zero at the central axis of the pipe and are maximal at the pipe wall. If the shear stresses at a given radial position are higher than the concrete bulk yield stress, then shearing of the bulk takes place. As a consequence of and in dependence on the properties of concrete and pumping conditions, concrete can flow in the slip flow mode, i.e. very thin slip layer + unsheared plug, or in the slip-plus-shear flow mode, slip + partial shear of bulk + plug $[13,27]$. Kaplan et al. [27] introduced analytical models for predicting concrete pumping pressure in the cases of slip and slip-plus-shear flow modes using rheological parameters for bulk $\tau_{0, B}, \mu_{p, B}$ and for interface $\tau_{0, L L}, \mu_{p, L L}$ as well as geometrical data of the pipeline. In the case of infinite brick extrusion with stiff material, the dynamic yield stresses and plastic viscosities are a few hundred $\mathrm{Pa}$, and few $\mathrm{Pa} \cdot \mathrm{s}$, respectively.

Whereas in the case of free flow deposition, these values are few tens of Pa and few tens of $\mathrm{Pa} \cdot \mathrm{s}$. Although the free flow material has lower yield stress, this does not necessarily mean lower pumping pressure losses in comparison to infinite brick extrusion, in which the high yield stress bulk does not deform during pumping, as proven in earlier research on pumping [23, 24]. Assuming a flow rate of $5 \mathrm{~m}^{3} / \mathrm{h}$ in a DN125 pipeline, the pressure loss per unit length can be in the range of $3.5 \mathrm{kPa} / \mathrm{m}$ for the infinite brick case and $5 \mathrm{kPa} / \mathrm{m}$ in the case of free flow deposition. This translates into pumping pressures of $70 \mathrm{kPa}$ and $100 \mathrm{kPa}$ for a DN125 pipeline of length $20 \mathrm{~m}$, respectively. Similarly, higher pressure losses are expected in the case of free flow deposition printable concrete than infinite brick printable concrete when pumped in pipelines of smaller diameter e.g. DN50.

The optimal rheological requirements of the material with respect to pumping are in competition with those favorable in respect of deformation behavior after layer deposition. In general, printable concretes are supposed to have high static yield stress to overcome gravitational and other forces acting after material deposition. The influence of high structural buildup and thixotropy rates of 3D-printable concretes, especially those used in infinite brick extrusion on pumping behavior have yet to be investigated. De Schutter and Feys [13] emphasized that "short interruptions during pumping lead to major difficulties in resuming pumping operations due to the sometimes tremendous effect of internal structural buildup". With large-scale pumping tests, they have observed that a 20-minute delay leads to an increase of pressure loss by $50 \%$ for a mixture with a structural buildup rate $\mathrm{A}_{\text {thix }}$ of $0.3 \mathrm{~Pa} / \mathrm{s}$. Despite increasing the pumping pressures to $35000 \mathrm{kPa}$, the pumping operations could not be resumed after the delay. Therefore, pumping very high-yield-stress concretes or, pumping chemically accelerated concrete may not be an optimal solution for large-scale, extrusion-based additive fabrication. 
An alternative solution is to pump low viscous and low yield stress concretes over the long distance and then activate them at the printhead, shortly before deposition. Such an approach requires the use of inline, second stage mixing techniques to ensure precise dosage and uniform homogenization of the admixture; see Section 5. Note that even in the case of free flow deposition, it is necessary to ensure that the rheological properties are sufficiently high to prevent filtration under high-pressure and segregation.

The methodology in characterizing the pumping-relevant rheological properties of concrete and lubricating layer, and the prediction of pumping pressures is a considerable challenge. The inadequacy of empirical design charts, which consisted mostly of a slump or spread parameter [13], has been overcome with recent, advanced test approaches and prediction models [28, 29, $30,31,32]$. However, most of these approaches require the accurate quantification of the concrete's and the LL's rheological properties, which has proven challenging for high yield-stress, printable concretes [33].

Numerical models can help in understanding the SIPM during pumping and characteristics of LL, as well as predicting pumping pressures. However, such tools have so far been simplified by the assumption of either a single-fluid homogeneous medium [23, 24, 25, 28, 34] or discrete granular elements [35]. In the case of concretes with high granular fractions, the interactions between aggregate and paste are crucial. Fluid-solid numerical models coupled with the modelling of time- and shear-dependent variations of pumping characteristics are yet to be developed.

The pumping process can alter the rheology of concrete, for example, due to dispersion of cement particles at higher shear rates, activation of residual superplasticizer, or air-induced by pistons. However, earlier observations of pumping-induced changes in concrete yield stress are inconclusive $[28,36]$. This can cause critical consequences for the continuity of the extrusion process or the stability of the resulting extruded layers, respectively, as a consequence of the increase or decrease in yield stress, thus necessitating further research to develop inline rheology monitoring tools that can be embedded, for instance, in the printhead.

\subsection{Extrusion}

In the context of additive fabrication, the extrusion step can be considered as the action of conferring the shape of its section to the deposited layer of cementitious material. This step is performed by forcing the material through a section contraction. This complex flow system has been studied extensively, providing insights into the rheology of visco-plastic fluids $[36,37$, $38,39,40]$. However, when dealing with cement-based materials, especially with a view to the additional plastic materials used in the "infinite brick" extrusion approach [10], i.e. to material with yield stresses higher than several $\mathrm{kPa}$, extrusion-induced segregation has been reported in the literature due to the multiphase nature of the cementitious materials under study [33, 41, 42, 43]. Such behavior can be described as competition between a) the cementitious materials' characteristic drainage time that is the result of the pressure drop at the extruder die and b) the extrusion time [33]. If the drainage time is shorter than the extrusion time, segregation is likely to occur, leading to the material's stiffening. For stiff cement-based mixtures which are close to the solid randomly packed fraction, drainage can also drastically change the material's rheological behavior from plastic to frictional [29, 33, 41, 43]. Such types of behavior are likely to induce surface defects or, more damaging, a stoppage of flow. Hence, securing a sufficient extrusion flow rate helps reduce the effect of drainage.

Another solution is to add external energy in such a way as to ease the flow, reducing wall friction and locally liquefying the cementitious materials. Such energy-based approaches to extrusion are a recent field of interest that has not been widely studied yet. Among these methods is local vibration of the cementitious material, which was studied to reduce the apparent 
yield stress of the material and to allow for a reduction of the extrusion pressure due to contraction flow [30].

The effect of vibration on an extrudate surface produced with a screw extruder can be seen in Figure 5, which indicates cracks which appear on the extrudate surface when no vibration is applied. When adding adapted vibration, the extrudate surface becomes smooth, and for even higher values of vibration energy, the extrudates are no longer able to withstand gravitational force.

The strategy of using vibration not only for facilitating material transport in the large printhead but also for extrusion-based material deposition was used by the HuShang Tengda company [31]. Because of the vibration of the nozzle orifice, relatively stiff, "ordinary" concrete could be deposited layer-wise and compacted in the process according to the personal observation of this article's first author. Note that for the purposeful use of such an approach a precise determination of the area of influence of vibration is required since the action of vibration on the already deposited layer could compromise the structural buildup process and lead to collapse of the printed layers. Some studies on the effects and influence zones of vibration have been carried out, but they are limited to the axisymmetric case of a vibration needle immersed in concrete $[32,44]$. Further studies on the influence of vibration on cementitious materials' extrusion flow are therefore necessary, specifically in the context of additive fabrication.

For printable cement-based materials, which are usually highly thixotropic, understanding the effect of vibration of extruded layers is a complex task, the zone of influence might be smaller than is usually predicted [44]. Alternatively to vibration, it is possible to use the electric potential difference within the steel extruder to promote the formation of a lubricating layer at the extruder's inner walls [45, 46]. Local application of a magnetic field is also envisaged to change the rheology of cementitious materials containing magneto-sensitive particles that can thus be uniformly oriented $[2,47]$. While such approaches seem promising, substantial additional efforts are required to assess the effect of those external energy applications on the extrusion flow of cementitious materials in the context of additive fabrication. In the first place, the determination of the precise region of influence of external solicitation is mandatory, since such influence could compromise the stability of the already printed layers.

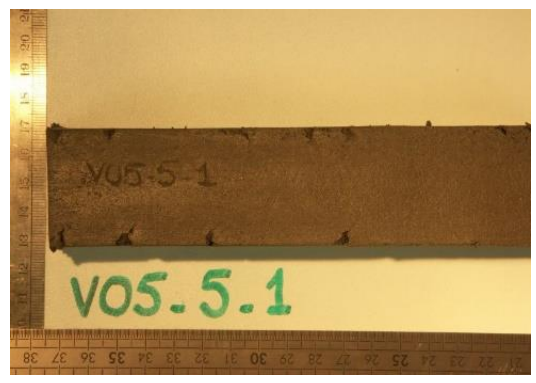

a) No vibration

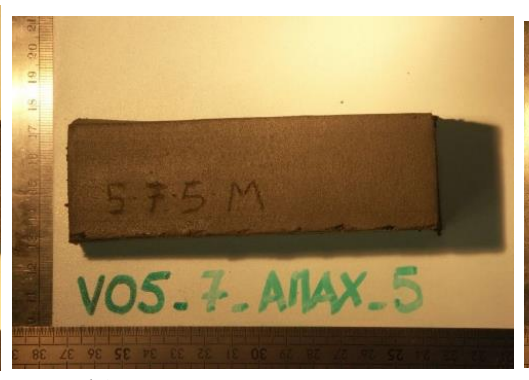

b) Frequency $7 \mathrm{~Hz}$ Amplitude $12 \mathrm{~mm}$

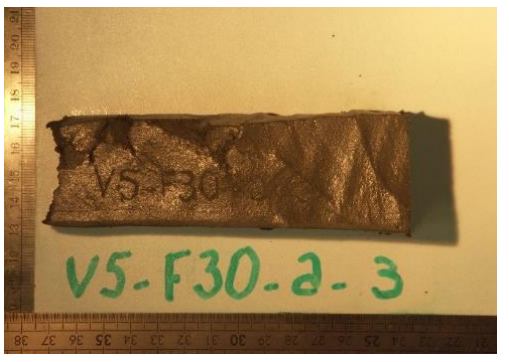

c) Frequency $30 \mathrm{~Hz}$

Amplitude $12 \mathrm{~mm}$

Figure 5. Effect of external vibration on the surface of extruded mortar (same screw rotational velocity of $5 \mathrm{rpm}$; mix design can be found in [30].

Furthermore, the design of the die is crucial because it governs the orientation and shape of the layer of material being deposited [6, 48]. Likewise, the velocity profile is important to control within the cross-section of the extruder in order to ensure proper placement of the layers and good adherence between layers [6]. Additionally, the extrusion flowrate should be controlled and estimated based on the rheological behavior of the cementitious materials, since the velocity of the material leaving the extruder has to be adjusted to the robotic arm to control the section 
of the deposited layer; see also Figure 3. Finally, some shapes of the nozzle make it necessary 378 to rotate the nozzle when printing curves.

379 Moreover, in the case of accelerated mixes, mostly using chemical admixtures, it is important 380 to use die geometries which prevent the formation of a dead zone, since the material "captured" there can harden during the process and eventually lead to process stoppage due to blockage. Consequently, mastering the flow behavior within the extruder leads to better control of the material's residence time in the die and avoid the buildup of heterogeneities, thus facilitating an adequate flow rate and trouble-free material deposition.

While the velocity profiles within an extruder have been studied for the simplest case of axisymmetric ram extrusion [38, 36, 41, 49], no study has dealt with the determination of the strain and stress fields within the extruder for complex die or nozzle geometries. Hence, there is need to provide numerical tools which can predict accurately the flow of cementitious materials through nozzles of any given geometry.

A last open question deals with the study of the flow of cementitious materials in a hopper screw geometry or in a progressive cavity pump extruder [21]. Predicting the cementitious flow rate from its rheological and tribological behavior and from the screw's rotational velocity is a challenge. Adequate numerical and analytical tools appropriate to the rheological properties of a given cement-based material are much required to ensure the continuous and controlled flow rate of the materials during extrusion.

\section{Dispersion in the printhead}

Many printing techniques involve a so-called acceleration of the material during or after deposition. Most of these techniques rely on the incorporation at the printhead level of either a chemical accelerator able to modify the silicate/aluminate balance and accelerate one of these hydration reactions, or an organic flocculant able to bridge the finest particles in the system. They could also rely on the mixing of the material with an alternative binder such as aluminate-based substances [50]. The former strategy (dispersion) involves amounts of products below a very few percent while the latter (mixing) often involves amounts above $10 \%$ by volume. All the strategies above lead to a faster and enhanced phase-change of the printed material, allowing for higher building rates and higher productivity. Moreover, these strategies allow for the mixing, pumping, and feeding of the robot with an extremely fluid material, which then turns into a pseudo-solid once the accelerator is added. However, these strategies require the dispersion of an active agent in the printhead or the mixing of a slurry, both of which give rise to several difficulties in terms of printhead design. The authors have focused here on dispersion.

411 From a process point of view, as soon as a dispersion technology is involved as a sub-process, residence (or retention) time of the material in the dispersing zone becomes a key parameter [51]. Considering that the nozzle cross-section is often close to the cross-section of the layer, the average material velocity in the printhead is on the order of the nozzle velocity itself (typically from 1 to $10 \mathrm{~cm} / \mathrm{s}$ [9]). Since most printheads' overall lengths are in the order of several tens of centimeters, the residence time should vary between 1 and $100 \mathrm{~s}$.

The accelerators used in additive manufacturing are either inorganic compounds with sizes of less than one nanometer or organic macromolecules of sizes on the order of 100 nanometers [52]. Although the validity of the Stokes-Einstein equation (see Eq. 1) fades when the size of the molecules gets closer to the size of the molecules of the solvent, it is used here to estimate the typical diffusion length from the natural diffusion coefficient of these accelerators. 


$$
D=\frac{k T}{6 \pi r \mu}
$$

where $k$ is the Boltzmann constant, $T$ the temperature in Kelvin, $r$ the size of the accelerator molecule and $\mu$ is the viscosity of the solvent. The typical diffusion length is of the order of $\sqrt{D t}$, where $\mathrm{t}$ is the residence time. This leads to typical diffusion lengths between a few micrometers and a few hundred micrometers. Consequently, even for the smallest printheads for pastes, full dispersion of accelerators in the nozzle cross-section cannot rely on natural diffusion alone, requiring additional dispersion capacity. As the viscosity of cement-based materials is too high to allow for turbulent dispersion, it is in the field of convective mixing that solutions do exist $[53,54]$.

The idea behind convective mixing relies on the creation of a secondary flow in the nozzle so that the distribution of the accelerator molecules is allowed. By shearing the material and, hence, distributing the accelerator in sheared material layers, one can reach, after a sufficient residence time, the situation in which the typical distance between two sheared material layers is on the order of the typical diffusion length estimated above.

From a technological point of view with respect to the newest existing solutions, this translates into either so-called static mixers or screw-mixing devices. The former are immovable, as indicated by their description, and it is the overall flow of the material around the surface of the static mixer that disperses the accelerator or other admixture, such as pigments. The latter are simply additional mixing systems with their own controls. Both are inserted into the printhead. The dispersion intensity of the static mixer is proportional to the flow rate in the printhead, while at the same time it is an independently tunable parameter in the case of the screw mixer.

The above features have not been studied in detail for the specific conditions and requirements of extrusion-based printing with cement-based materials as yet. Printheads and their mixing devices are accordingly designed by trial and error. Numerical simulations $[55,56,57]$ could in the future allow for a better understanding and progress in printhead design.

\section{Load-bearing and deformation behavior after deposition}

\subsection{Object failure during manufacturing}

\subsubsection{Failure modes}

Additive manufacturing methods of cementitious materials are, by definition, set apart from "conventional" formative methods by the absence of molds. As a result, objects may collapse during the manufacturing process. Considering that the material resistance is initially low relative to its self-weight, the 'buildability' $[58,59]$ of a mortar is an important property in assessing its suitability for printing. The term, however, refers to a range of processes and properties that require elaboration in order that it becomes a meaningful concept.

At present, two mechanisms have been recognized as causes of collapse in extrusion-based, layered 3D concrete printing during manufacturing:

- material failure (Figure 6a), and

- loss of stability (Figure 6b).

Material failure occurs when the material strength is exceeded, resulting in yielding, flow, or fracture, whereas stability loss is defined by a loss of equilibrium of forces and moments, initiating uncontrolled deformations or displacements. 


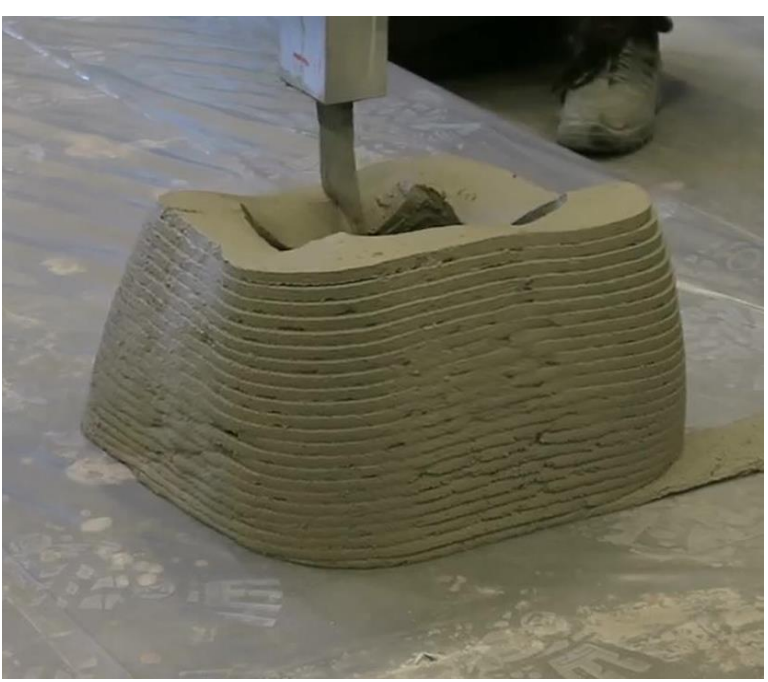

a)

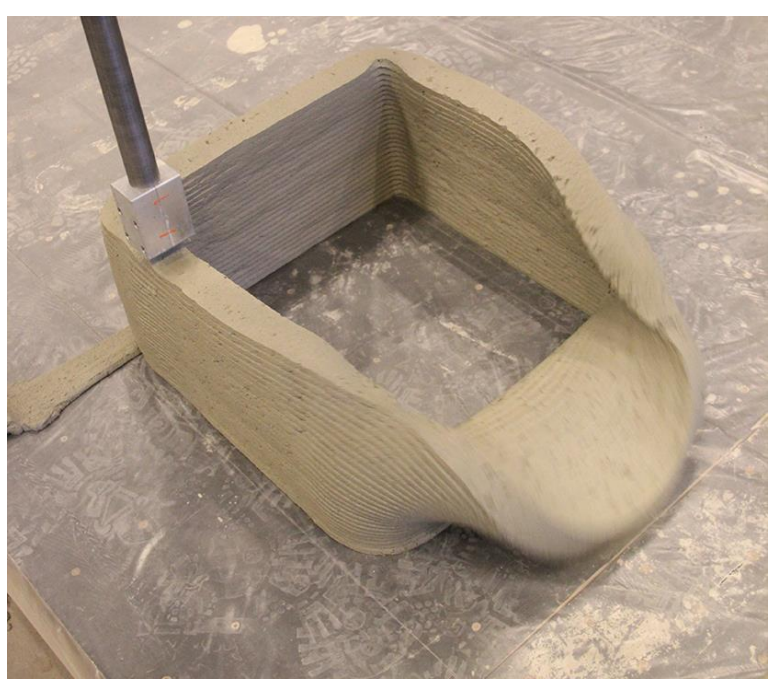

b)

Figure 6. Collapse in extrusion-based additive manufacturing: a) material failure, b) stability failure [60].

Either mechanism is triggered by a combination of support, load, and geometry conditions - of which the former is generally constant, but the latter do change over time due to the gradual buildup of the object during manufacturing. In the hitherto limited number of developed prediction models for object failure during printing of cementitious materials, the centered selfweight of the material is considered as the sole load condition exerted on the print object. This allows the formulation of relatively simple relations between material strength and build height; see Section 6.1.2, Eqs. 2 and 3. Several additional types of loading are conceivable, such as kinematic pressure from the deposition of filament, vertically or horizontally, when layers are squeezed together, non-vertical pressures from supporting filler materials as in Figure 7, eccentric loading due to accidental misalignment of layers, or purposefully created cantilevering geometries.

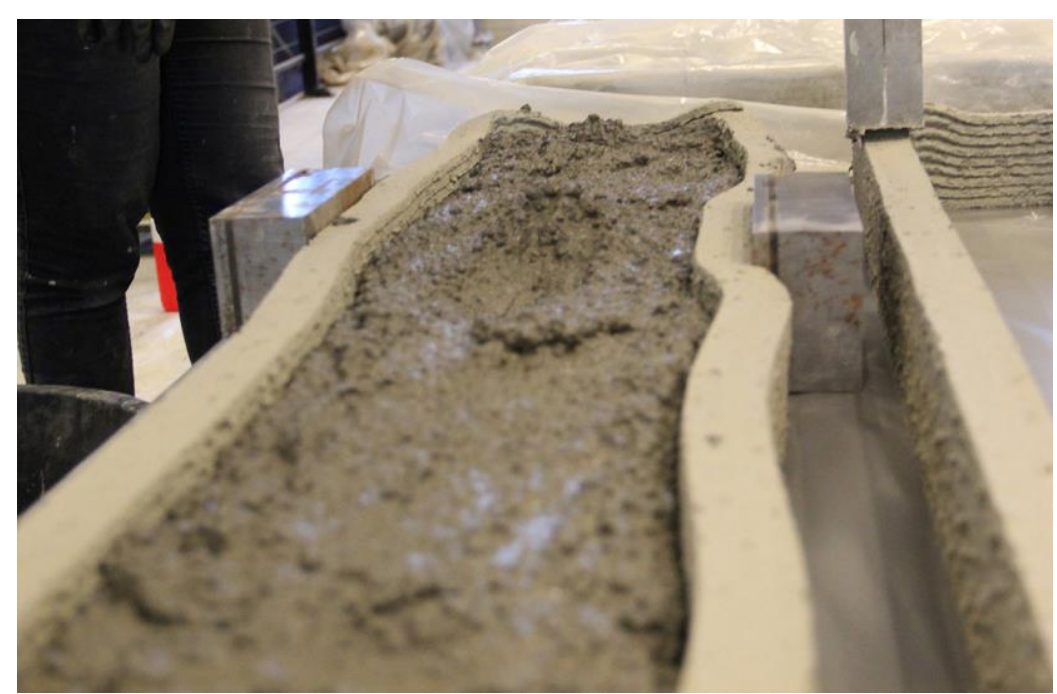

Figure 7. Structural failure of an object during 3D printing due to horizontal loading by a highly fluid infill material

In any specific case, 'buildability' - or the resistance to failure during printing - is not only dependent on the material's characteristics but, also on the object design, e.g. size, geometry, and process parameters such as print speed. For example, at otherwise identical print settings, 
a straight wall may fail sooner than a curved wall of the same path length due to the increased stability provided by the curved wall's bend(s). In another case, a short wall could topple over at fewer layers than a long wall, even though buckling is determined by the perpendicular section, which is identical for both, because of the slower buildup and longer time for the material to develop strength and rigidity [61].

To define the initiation of material failure, i.e., fracture, yielding, etc., many criteria have been proposed [62], but it is not immediately clear which one(s) is (are) suitable for the mortars that are used in extrusion-based concrete printing. This is primarily due to the transition that printable cementitious mortars undergo from a non-Newtonian fluid state to a solid state during the manufacturing process. This process, which usually takes several hours but can be as short as several minutes when fast-setting cements or accelerators are applied, includes reversible physical, e.g., flocculation-induced thixotropy, as well as irreversible chemical phenomena (hardening due to cementing reactions). As a result, both strength and rigidity increase over time, which in rheology is often labelled as the structuration rate of the yield stress, $A_{\text {thix. }}$.

The selection of a suitable criterion to characterize material failure is further complicated by the fact of printable mortars having considerably varying levels of initial yield stress and rigidity, associated sheared or un-sheared flow regimes, and different structuration and hardening rates as well while the level of material development in an individual print depends on the print strategy and object design. Thus, the appropriate material failure criterion may depend on the mortar, process and design characteristics in any specific case - further increasing the challenges in developing generic prediction models.

Considering the fluid-to-solid transition, the material could be assumed to behave as a highly viscous fluid or as an initially very compliant visco-elastic or elasto-plastic solid. In the case of the former, concepts from the field of fluid mechanics and rheology should be applied, whereas solid mechanics should be applied in the case of the latter. The approach selected governs the definition of material properties and the experimental methods required to determine them. Vice versa, it should be recognized that not all experimental methods are suitable for all ages of print mortar; for example, some mortars are too stiff to perform rotational rheometry without plug forming, while others may be too fluid to perform unconfined compression tests. Indeed this could serve as an indicator regarding the applicability of certain theoretical approaches.

The approach that is to be taken also determines the types of analysis that may be performed to quantify 'buildability'. A solid approach governed by mechanics allows recognition of material failure under anisotropic, multi-axial stress states as well as failure due to loss of stability. In fluid mechanics, only isotropic stress states are considered, and stability analyses are highly unusual. However, it is more appropriate for flow analyses.

\subsubsection{Approaches in literature}

In the literature, a range of different approaches has been suggested to quantify buildability, with the lack of unanimity being caused by the sheer number of aspects discussed above. The summary provided in Table 2 shows that the spectrum of models not only stems from the fundamental approach to the material state, but also from other associated issues related to experimental methods, validation, time dependency, and so on. In the elaboration provided below, some quantitative data as well are presented for comparative purposes. However, it should be noted that these values have been obtained from significantly different experimental methods, the validity of which may still be under debate. 
Table 2. Approaches to the quantification of 'buildability' in literature.

\begin{tabular}{|c|c|c|c|c|c|c|c|}
\hline Publication & \begin{tabular}{|l|} 
Failure \\
mode(s)
\end{tabular} & Theory & $\begin{array}{l}\text { Material failure cri- } \\
\text { terion }\end{array}$ & $\begin{array}{l}\text { Experimental Proce- } \\
\text { dure }\end{array}$ & Time effect & Geometrical Model & Validation \\
\hline$[63]$ & Material & Solid mechanics & Drucker-Prager & $\begin{array}{l}\text { Unconfined uniaxial } \\
\text { compression }\end{array}$ & Constant & $\begin{array}{l}\text { 2D in vertical section } \\
\text { plan }\end{array}$ & $\begin{array}{l}\text { Unconfined uniaxial } \\
\text { compression }\end{array}$ \\
\hline$[15]$ & Material & Rheology & $\begin{array}{l}\text { Yield stress of non- } \\
\text { Newtonian fluid }\end{array}$ & Rotational rheometer & Linear \& exponential & vertical stack, 1D & $\begin{array}{l}\text { Unconfined uniaxial } \\
\text { compression }\end{array}$ \\
\hline$[1]$ & Material & Rheology & $\begin{array}{l}\text { Yield stress of non- } \\
\text { Newtonian fluid }\end{array}$ & $\mathrm{n} / \mathrm{a}^{*}$ & Linear & vertical stack, 1D & $\mathrm{n} / \mathrm{a}$ \\
\hline$[17]$ & $\begin{array}{l}\text { Material, } \\
\text { stability }\end{array}$ & Solid mechanics & Mohr-Coulomb & $\begin{array}{l}\text { Shear box }+ \text { uncon- } \\
\text { fined uniaxial com- } \\
\text { pression }\end{array}$ & Linear & $\begin{array}{l}\text { vertical stack, 2D in } \\
\text { vertical section plan }\end{array}$ & Cylindrical print trial \\
\hline$[64]$ & $\begin{array}{l}\text { Material, } \\
\text { stability }\end{array}$ & Solid mechanics & Mohr-Coulomb & $\begin{array}{l}\text { Shear box }+ \text { uncon- } \\
\text { fined uniaxial com- } \\
\text { pression** }\end{array}$ & $\begin{array}{l}\text { Linear \& exponential } \\
\text { decaying }\end{array}$ & $\begin{array}{l}\text { Linear wall struc- } \\
\text { tures, 2D and 3D }\end{array}$ & Wall print trials \\
\hline$[10]$ & $\begin{array}{l}\text { Material, } \\
\text { stability }\end{array}$ & Mixed & $\begin{array}{l}\text { Yield stress of non- } \\
\text { Newtonian fluid }\end{array}$ & $\begin{array}{l}\text { Rotational rheome- } \\
\text { ter* }\end{array}$ & linear \& exponential & vertical stack, 1D & $\mathrm{n} / \mathrm{a}$ \\
\hline$[65]$ & Material & Rheology & $\begin{array}{l}\text { Bulk yield stress from } \\
\text { Benbow-Bridgewater } \\
\text { model }\end{array}$ & Ram-extruder & Constant & vertical stack, 1D & Cylindrical print trial \\
\hline$[66]$ & Material & Solid mechanics & Shear stress & $\mathrm{n} / \mathrm{a}^{* *}$ & Linear & $\begin{array}{lll}\text { Vertical } & \text { stack, } & \text { 2D } \\
\text { along } & \text { print } & \text { path } \\
\text { length } & & \end{array}$ & $\mathrm{n} / \mathrm{a}$ \\
\hline$[61]$ & $\begin{array}{l}\text { Material, } \\
\text { stability }\end{array}$ & Solid mechanics & Mohr-Coulomb & Tri-axial compression & Linear & $\begin{array}{l}\text { vertical stack, 2D in } \\
\text { vertical section plan }\end{array}$ & Wall print trials \\
\hline$[67]$ & Material & Rheology & $\begin{array}{l}\text { Yield stress of non- } \\
\text { Newtonian fluid }\end{array}$ & Rotational rheometer & Bi-linear & vertical stack, 1D & Cylindrical print trial \\
\hline
\end{tabular}


Di Carlo et al. [63] investigated the compressive strength of a fresh print mortar using a uniaxial compression test and found compressive strengths of $5.52 \mathrm{kPa}$ to $88.3 \mathrm{kPa}$ and moduli of elasticity of $77.9 \mathrm{kPa}$ to $1241 \mathrm{kPa}$, for mortars at ages of 11 to 288 minutes (strength $10.7 \mathrm{kPa}$ after 47 minutes). They recreated the experiments in a Finite Element Model (FEM) in which a Drucker-Prager failure criterion was applied.

Alternatively, Perrot et al. [15] presented a buildability approach based on the rheological yield stress $\tau_{c}$ of the print mortar as the material failure criterion, which was relatively easily obtained from rotational rheometry and validated against uniaxial compression tests on shallow samples. Eq. (2) presents the basis of their approach in slightly rewritten form, with $\alpha_{\text {geom }}$ a geometrical factor, $\tau_{0}(t)$ the time dependent yield stress of the mortar, $\rho$ its density, $g$ the gravitational acceleration, and $h(t)$ the time dependent object height:

$$
\alpha_{\text {geom }} \tau_{0}(t) \geq \rho g h(t)
$$

548

549

550

551

552

553

554

555

556

557

558

559

560

561

562

563

564

565

566

567

568

569

570

571

572

573

574

575

The yield stress of the mortar applied in that study developed linearly over time until reaching an approximate age of 40 minutes, from 4.13 to $6.29 \mathrm{kPa}\left(\mathrm{A}_{\text {thix }}=54 \mathrm{~Pa} / \mathrm{min}\right)$, but it developed exponentially when considering a time frame of 0 to 80 minutes. The validation experiments fit the predicted failure moments very well. Further experimental rheological data on printable mortars can be found in $[68,69,70]$.

Wangler et al. [1] adopted a very similar approach, but applied a von Mises plasticity criterion, by introducing a factor $\sqrt{3}$ into the buildability equation. On the other hand, a geometry factor was not applied. Rewritten, this yields:

$$
\tau_{0}(t) \geq \rho g h(t) / \sqrt{3}
$$

The first method to take both material and stability failure into account was presented by Wolfs et al. in [17], and further developed in $[61,71]$. This method is based on FEM expanded with time-dependent properties, and the adoption of the Mohr-Coulomb failure criterion, including the development of experimental procedures to determine the full failure envelope. The dual failure criterion of plastic yielding and elastic buckling requires the experimental determination of five time-dependent material properties: the apparent Young's modulus $E(t)$, Poisson's ratio $v(t)$, the cohesion $C(t)$, angle of internal friction $\varphi(t)$, and dilatancy angle $\psi(t)$. For two commercially available mortars this yielded linearly developing compression strengths from 5 to 90 minutes of $7.1 \mathrm{kPa}$ to $18.9 \mathrm{kPa}$ (rate: $139.6 \mathrm{~Pa} / \mathrm{min}$ ) and $2.8 \mathrm{kPa}$ to $29.7 \mathrm{kPa}$ (rate: $317.2 \mathrm{~Pa} / \mathrm{min}$ ), and moduli of elasticity of $80.2 \mathrm{kPa}$ to $186 \mathrm{kPa}$ (rate: $1244 \mathrm{kPa} / \mathrm{min}$ ) and $35.9 \mathrm{kPa}$ to $325 \mathrm{kPa}$ (rate: $3400 \mathrm{~Pa} / \mathrm{min}$ ). Suiker [64] introduced a parametric mechanistic model which focuses on the competition between elastic buckling and plastic collapse, and can be used to predict structural failure of straight, free-standing walls during 3D printing.

A mixed methodology combining the rheology material failure criterion with the stability considerations from solid mechanics was suggested by Roussel [10]. Besides (3), this yields (4), again, slightly rewritten, representing the material and stability failure criteria, respectively. Through the relation $E=2 G(1+v)$ between Young's modulus $E$, shear modulus $G$ and Poisson's ratio $v$ on the one hand, and the relation $\tau_{c}=G \gamma_{c}$ between yield stress, shear modulus and critical shear strain $\gamma_{c}$ on the other, the transition height can be determined according to (5), at which one failure criterion becomes dominant over the other.

$$
\begin{gathered}
E_{c}(t) \geq 3 \rho g h(t)^{3} / 2 \delta^{2} \\
h_{t}=2 \delta \sqrt{\frac{1+v}{3 \sqrt{3} \gamma_{c}}}
\end{gathered}
$$


Continuing from the material assumptions by Perrot et al. [15], Wangler et al. [1], and Roussel [10], Kruger et al. [67] suggested, rather than a linear structuration rate, a bilinear rate, which yielded a shear strength development of $1.15 \mathrm{kPa}$ to $2.73 \mathrm{kPa}$ at a re-flocculation rate of $\mathrm{R}_{\text {thix }}=$ $413 \mathrm{~Pa} / \mathrm{min}$ over the first $230 \mathrm{~s}$, and further up to $6.37 \mathrm{kPa}$ at 60 minutes at $\mathrm{A}_{\text {thix }}=64.8 \mathrm{~Pa} / \mathrm{min}$.

A rheological approach with a Benbow-Bridgwater model rather than a Bingham model was adopted by Chaves Figueiredo et al., [65]. This yields the material parameters bulk yield stress and shear yield stress, of which the former seems to be primarily responsible for the aspect of buildability.

Finally, an analytical model was proposed by Jeong et al. [66], who took the age of the material along the print path length into account. The shear strength (solid mechanics) was adopted as failure criterion without extensive elaboration.

\subsubsection{Research needs}

Many aspects surrounding in-print failures are still unclear. Globally three topics seem to be particularly in need of research.

First, little is known about the actual loads acting on in-print objects. Although self-weight, the most important load, can be established relatively easily, the effects of kinematic pressures, support materials, and eccentricities are not quantitatively known.

For material failures, the appropriate failure criterion or criteria need(s) to be established. A fundamental underlying question is in which cases and whether at all it is relevant to allow for anisotropic stress states for such a criterion, which requires considerably more complicated analyses and experimental procedures. The accuracy of buildability predictions based on different methods and associated material property experiments should be rigorously tested through extensive printing trials. Rather than focusing on a single case, such trials should encompass a range of different geometries, print speeds, print resolution, and object sizes as well as their being performed on different printing facilities to eliminate equipment-dependent bias. The development of a range of benchmark print geometries for comparative studies would be beneficial.

Once the theoretically most satisfying approach has been found, the correlations between various (experimental) methods may be studied to determine which approach is to be preferred from a practical standpoint. In this campaign it should be recognized that the appropriateness of a certain approach may depend on the properties of the individual print mortar or its relationship to the physical condition. For instance, it should be expected there are thresholds of yield stress or viscosity above or below which solid or fluid mechanics are clearly more applicable, but it is conceivable that transitional stages exist in which each approach may work similarly well and the preferred approach may depend on other factors such as practical arguments. Only a few multi-modal material characterizations have yet been performed $[72,73]$, and correlation attempts to link different approaches are still minimal.

Finally, the transitory characteristics of print mortars should be more comprehensively studied. Current buildability models only consider properties such as strength and modulus of elasticity as a linear or non-linear function of time. It is, however, likely that such developments are a function of multiple parameters, the most obvious of which is temperature. The temperature dependency of buildability has tentatively been established [74], which indicates that time-dependent development functions must be derived for a multitude of temperatures, or through a combined parameter such as maturity, indeed a combination of time and temperature, as has already been defined for concrete of ages beyond the setting time. Considering printing's not 
always taking place under fully conditioned environmental conditions, this should be considered relevant. Possibly other parameters, such as the shearing history of the mortar may also need to be included.

\subsection{Deformation behavior}

\subsubsection{Deformation mechanisms}

The actual deformations which occur in cementitious mortars during selective material deposition by extrusion before failure have hardly been studied. Two mechanisms should be distinguished. First, in some cases, depending on the solidification strategy of the process in question (cf. Sections 3 and 4), the mortar flows briefly upon deposition before a rapid increase in strength initiated by viscosity modifiers or accelerators stops the visco-plastic flow and the material assumes a stable shape.

Other processes deposit mortars in an unsheared condition, directly in a shape-stable state, which can last from minutes to hours. The visco-elastic deformations that may occur during this period may influence both the geometrical conformity and the object stability during printing.

To determine the elastic deformations, the apparent Young's modulus E may be determined from unconfined compression experiments directly; cf. Section 6.1.2. Obtaining E through the shear modulus $\mathrm{G}$ taken from rheometric tests does not seem feasible, as this requires the assumption of a value for the Poisson's ratio $v$.

646 Depending on which of the deformation mechanisms, flow or (visco-)elastic deformation, is being studied, different modelling approaches can be adopted: Computational Fluid Dynamics (CFD) for the former [75] or Finite Element Modelling (FEM) for the latter. A combination of both may be required to capture the full deformation and displacement behavior. The Discrete Element Method (DEM) might also be suggested, as it is suitable for granular materials and theoretically capable of modelling both flow and deformations $[76,77]$.

\subsubsection{Research needs}

The accurate prediction of deformations and displacements is relevant to geometry-related failure behavior, i.e., primarily stability failure and, to a lesser extent, material failure, but to issues of the geometric conformity of the finished product as well. Because little data on fresh mortar deformation behavior is currently available, more research into the related material properties is required. This includes the development of suitable experimental methods, for which some initial suggestions have been made in [8]. Modelling methods need to be developed and validated, which also calls for the establishment of suitable means of measurement during or after printing. The interaction between in-print failure and deformation behavior should be further explored.

\section{Physical properties and their evolving over time}

666 Viscosity is the measure of the internal resistance of a fluid to its being deformed by shear stresses. In this context the less viscous a fluid is, the easier it flows. Due to the flocculation and stiffening of the cement-based materials, the apparent viscosity of the cement-based material increases with time at rest. However, for yield stress this behavior is reversible in time since 
the mixing power is sufficient to break down the links between particles. Here it is important to note that the viscosity of the cement-based materials can evolve due to process-induced material variation during pumping or extrusion. Such variation can be associated, for example, with particle migration under shear flow.

\section{4}

675

676

677

678

679

680

681

682

683

684

685

686

687

688

689

\subsection{Yield stress}

Yield stress is the material property that denotes the transition between solid-like and fluid-like behaviors. On the microscale, interparticle forces between the solids in a suspension result in a yield stress that must be overcome to start flow. An applied stress lower than the yield stress will result in deformation behavior like that of a solid. In other words, yield stress is the minimum stress that makes the fluid flow as a viscous material. This minimum level of solicitation depends on the stress history of the cementitious materials. Consequently, static and dynamic yield stresses can be distinguished. Static yield stress is an increasingly important parameter that depends on shearing and resting periods and is related to microstructural buildup and is defined as the shear stress required to make the material flow, while dynamic yield stress can be defined as the yield stress measured under the steady-state flow of material with unstructured cement paste.

The major challenge associated with the 3D printing of cement-based materials is the determination of increase in static yield stress after a layer has been deposited. Since such measurements are not trivial; see e.g. [78]. And there are numerous activities on developing adequate test methods and protocols; see e.g. $[79,80]$.

\subsection{Thixotropy parameter / rate of structural buildup / structural breakdown}

Fresh cement-based materials undergo cement hydration, which impacts their physical and rheological behavior. It is this change in mechanical characteristics that allows the fresh material to build up and be able to support the increasing load generated by the successive deposits of the layers of the printed structure. Therefore, it is necessary to rely on the kinetics of the mechanical structural buildup of the material as they relate to the activity of cement in water [1, $15]$.

To understand why the cement material becomes rigid, it is necessary to take into account the organization of the network of cement grains in suspension in the water. After intense mixing culminating in de-structuring, the cement grains begin to flocculate under the influence of colloidal interactions. This flocculated lattice structure induces an increase in rigidity and strength, over a time period of several tens of seconds $[10,81]$. Then, over longer periods of time, the rapid formation of C-S-H linkages in the contact zones between the grains goes on to form the origin of the continued mechanical structural buildup of the cement material left at rest [81]. This phenomenon of the nucleation of the cement grains occurs during the period known as the dormant period, before the cement setting. These nucleations are a chemically irreversible phenomenon. However, if the power of the pumping and/or mixing system suffices, these links may be broken. It is important to note that in the 3D printing of cement-based materials, accelerators are often added to the cementitious materials leading to the early formation of other hydrates such as ettringite, monosulfate, and aluminate hydrates, which are responsible for the early increase in static yield stress.

Therefore, the parameters of mechanical behavior are subject to the structural buildup kinetics over time when the cement materials are left to set after being deposited in layers. To illustrate and describe this phenomenon, the changes in the stiffness and the yield stress values have often been reported by several researchers $[81,82,83]$. 
The increase in the progression of yield stress over time is often considered to be linear and, as such, allows a structural buildup rate to be defined as $\mathrm{A}_{\text {thix }}$ in $\mathrm{Pa} \cdot \mathrm{s}^{-1}[81,82,83]$. In this case, the equation is written in this way:

$$
\tau_{0}(t)=\tau_{0, t=0}+A_{t h i x} t
$$

with $\tau_{0, t}=0$, the shear yield stress of the material in a de-structured state and $t$ being the duration of the resting period of the material.

The linear modelling of shear yield stress is generally valid during the first hour of the resting period of the cement-based material [84]. Beyond that the change accelerates and the kinetics of the structural buildup become exponential $[85,86]$. This change in rates can be explained by the beginning of the setting, the increase of the solid volume fraction with the possible interpenetration of the C-S-H crystals created. Perrot et al. [85] proposed a law for the exponential progression of shear yield stress, tending towards the linear model over short time periods. This model is given by (7):

$$
\tau_{0}(t)=A_{t h i x} t_{c}\left(e^{t / t_{c}}-1\right)+\tau_{0, t=0}
$$

with $t_{c}$ as a characteristic time over which the behavior can be considered linear. The model of (7) can be used to describe the progression of the shear threshold over longer periods. Other more sophisticated models have recently been reported in the literature $[17,18,86]$. Some authors have even shown that a Von Mises-type plasticity criterion may ultimately not be wellsuited to account for the breakage of the material. Effectively, at a certain stage in the development of the setting, the behavior of the material displays a pressure-sensitive, granular type of behavior, probably related to the interconnection of the hydrates, then becoming sensitive to pressure. The mechanical behavior thus represents a progressive dissymmetry, with a resistance that is always higher in compression than in tension. Hence, the transition to hardened concrete behavior can be seen to start at this time.

Mantellato et al. [87] recently reported that the increase in the yield stress associated with an irreversible flow loss can be associated with an increase in the solid particles' specific surface induced by chemical cement hydration. At the same time the critical deformation decreases slightly with the hardening of the material $[10,17,18]$.

Additionally, this increase in stiffness over time is reflected in an increase in the elastic modulus. This increase in stiffness and strength allows the material deposited to withstand the increased loads associated with the printing of the structure. In this way it is possible to calculate and predict the optimal manufacturing speeds to guarantee the stability of the structure printed and to ensure the compensation for the elastic deformation.

\subsection{Measurement procedure of rheological and early age properties}

To assess the stability of the in-print cementitious materials, it is necessary to follow the evolution of the materials' early-age properties after being deposited. Then effort must be made to monitor inline the evolution of stiffness and strength of the cementitious material.

If oscillatory rheometry and ultrasound test measurements are reliable methods to estimate the evolution of a material's elastic modulus over time, they require expensive and sensitive devices that are not easy to implement in a printing environment [50].

To relieve this situation, instantaneous or continuous penetration tests or gravity-induced flow tests are being developed in order to monitor, using simple tools, the evolution of the materials' properties over time. For example, the penetration test (cone plunger) was used by filling the cone mold with mortar in two layers, then releasing the cone plunger, thus allowing the plunger 
to penetrate into mortar under its own weight [88]. Good relationships $\left(\mathrm{R}^{2}=0.86-0.89\right)$ between the penetration and slump flow were established. It was reported that the increase in the penetration values followed the same trend with the increase in the slump flow of mortar.

\section{$761 \quad$ 8. Summary and conclusions}

3DCP offers great potential to facilitate development towards a sustainable Construction Industry 4.0, tackling existing problems such as low productivity and shortage of skilled labor in the process. Among 3DCP approaches, those based on material extrusion seem to be particularly promising at this stage with respect to both overall technological readiness level and economic viability. This article focuses on this specific 3DCP approach. The explanations and statements are the result of collective research performed by the authors in the framework of the RILEM Technical Committee 276 "Digital fabrication with cement-based materials".

Three main categories of extrusion-based 3DCP are identified as: i) extrusion of stiff material, similar to conventional extrusion, ii) extrusion of flowable material with or without addition of admixture(s) in the printhead, and iii) extrusion of material using additional energy input, e.g. vibration to facilitate delivery and deposition of stiff mixtures. To each category and each production step, i.e., transportation of build material, printhead process, deformation of build material during deposition, and behavior of build material after deposition, relevant processes and corresponding physical fundamental are presented. In particular, gravitational flow, pressureinduced flow during pumping and extrusion, and dispersion of admixture in the printhead are considered. Also, attention is paid to the load-bearing and deformation behavior of the material/printed object after material deposition. Two major failure modes are defined for object failure during manufacturing, both crucial to buildability: i) material failure, where the material strength is exceeded, and ii) stability failure due loss of the equilibrium of forces and moments. Various models to estimate buildability are presented and critically discussed. Deformation mechanisms are explained as well. Finally, key physical properties of cement-based materials in the fresh state - viscosity, yield stress, and thixotropy - as well as their evolution in time are identified, followed by brief remarks on measurement procedures of rheological and early-age properties.

In summarizing the knowledge as presented, it can be concluded that underlying physics are well understood for most processes of large-scale additive manufacturing by material extrusion. This understanding can and should be utilized for the purposeful design of 3DCP systems rather than trying to use a trial-and-error approach in shaping the 3DCP process. Purposeful, systematic approaches based on the associated physics should facilitate material development and mechanical engineering design as well as optimize process regimes and process control. For some processes analytical, scientifically based formulas already offer reasonable predictions with respect to material flow in the case of relatively simple geometries. Nevertheless, further research is needed in order to enable the development of reliable tools for quantitative process analysis and for predictions based on the underlying physics. The major challenges in analyzing 3DCP systems arise out of the complexity of flow regimes and patterns in various production steps as well as the time- and shear-history-dependent behavior of cement-based materials, which are inherently complex multiscale, multiphase, densely packed suspensions. Much effort needs to be invested in studying and describing specific flow behavior and developing adequate testing technics to quantify key material parameters. Numerical simulation can contribute greatly to analyze flow processes under consideration of complex geometric boundaries; this has the potential to be developed into a powerful design tool for shaping the 3DCP processes. The derivation of model parameters is the main issue here, requiring appropriate experimentation. This deliberation holds true as well for the estimation of buildability. Material behavior, geometry 
of the printed element, particularities of printing process, and other aspects need to be considered collectively. While analytical formulas may deliver reasonable predictions for relatively simple cases, numerical simulation constitutes a promising approach for analysis of more complex cases.

\section{Acknowledgements}

The authors acknowledge with gratitude the support of RILEM, through which this work was carried out and, in particular, the support of the members of Technical Committee 276-DFC "Digital fabrication with cement-based materials".

The work was also supported by: The Deutsche Forschungsgemeinschaft (DFG, German Research Foundation), Project Number 387152958 (GZ: ME 2938/20-1), within the priority program SPP 2005 OPUS FLUIDUM FUTURUM - Rheology of reactive, multiscale, multiphase construction materials; The Innovation Fund Denmark (Grant no. 8055-00030B: Next-Generation of 3D-printed Concrete Structures). Part of this work has been carried out within the framework of the project DiXite. Initiated in 2018, DiXite is part of I-SITE FUTURE, a French initiative to answer the challenges of the sustainable city.

\section{References}

[1] T. Wangler, E. Lloret, L. Reiter, N. Hack, F. Gramazio, M. Kohler, M. Bernhard, B. Dilenburger, J. Buchli, N. Roussel and R. J. Flatt, "Digital concrete: opportunities and challenges," RILEM Technical Letter, pp. 67-75, 2016.

[2] G. De Schutter, K. Lesage, V. Mechtcherine, V. Nerella, G. Habert and I. Agustí-Juan, "Vision of 3D printing with concrete - Technical, economic and environmental potentials," Cement and Concrete Research, vol. 112, pp. 25-36, 2018.

[3] R. Buswell, R. Soar, A. Gibb and A. Thorpe, "Freeform Construction: Mega-scale Rapid Manufacturing for construction," Automation in Construction, vol. 16, no. 2, pp. 224-231, 2007.

[4] V. Mechtcherine, V. Nerella, F. Will, M. Näther, J. Otto and M. Krause, "Large-scale digital concrete construction - CONPrint3D concept for on-site, monolithic 3Dprinting," Automation in Construction, vol. 107, art. 102933, 2019.

[5] D. Lowke, E. Dini, A. W. D. Perrot, C. Gehlen and B. Dillenburger, "Particle-bed 3D printing in concrete construction - Possibilities and challenges," Cement and Concrete Research, vol. 112, pp. 50-65, 2018.

[6] T. Salet, Z. Ahmed, F. Bos and H. Laagland, "Design of a 3D printed concrete bridge by testing," Virtual and Physical Prototyping, vol. 13, pp. 222-236, 2018. 
[7] N. Valencia, "World's first 3D printed bridge opens in Spain," 2017. [Online]. Available: https://www.archdaily.com/804596/worlds-first-3d-printed-bridge-opens-in-spain. [Accessed 10 December 2017].

[8] R. Buswell, W. R. Leal de Silva, F. P. Bos, R. Schipper, D. Lowke, N. Hack, H. Kloft, V. Mechtcherine, T. Wangler and N. Roussel, "The RILEM process classification framework for defining and describing Digital Fabrication with Concrete," Cement and Concrete Research, vol. (submitted for the Special Issue), 2020.

[9] R. Buswell, W. Leal de Silva, S. Jones and J. Dirrenberger, "3D printing using concrete extrusion: A roadmap for research," Cement and Concrete Research, vol. 112, pp. $37-49,2018$

[10] N. Roussel, "Rheological requirements for printable concretes," Cement and Concrete Research, vol. 112, pp. 76-85, 2018.

[11] K. Kovler and N. Roussel, "Properties of fresh and hardened concrete," Cement and Concrete Research, vol. 41, pp. 775-792, 2011.

[12] N. Roussel, A. Lemaître, R. Flatt and P. Coussot, "Steady state flow of cement suspensions: A micromechanical state of the art," Cement and Concrete Research, vol. 40, p. 77-84, 2010.

[13] G. De Schutter and D. Feys, "Pumping of Fresh Concrete: Insights and Challenges," RILEM Technical Letters, vol. 1, pp. 76-80, 2016.

[14] N. Roussel and P. Coussot, "“Fifty-cent rheometer" for yield stress measurements: From slump to spreading flow," Journal of Rheology, vol. 49, pp. 705-718, 2005.

[15] A. Perrot, d. Rangeard and A. Pierre, "Structural built-up of cement-based materials used for 3D-printing extrusion techniques," Materials and Structures, vol. 49, no. 4, pp. 1213-1320, 2016.

[16] G. Ovarlez and N. Roussel, "A Physical Model for the Prediction of Lateral Stress Exerted by Self-Compacting Concrete on Formwork," Materials and Structures, vol. 39, no. 2, pp. 269-279, 2006.

[17] R. J. M. Wolfs, F. P. Bos and T. A. M. Salet, "Early age mechanical behaviour of 3D printed concrete: Numerical modelling and experimental testing," Cement and Concrete Research, vol. 106, pp. 103-116, 2018.

[18] L. K. Mettler, F. K. Wittel, R. J. Flatt and H. J. Herrmann, "Evolution of strength and failure of SCC during early hydration," Cement and Concrete Research, vol. 89, pp. 288-296, 2016.

[19] C. Gosselin, R. Duballet, P. Roux, N. Gaudilliere, J. Dirrenberger and P. Morel, "Largescale 3D printing of ul-tra-high performance concrete - a new processing route for architects and builders," Materials \& Design, vol. 100, pp. 102-109, 2016. 
[20] F. Lo Monte, G. Zago, M. Cucchi and F. L., "Correlation between "very early" age fracture performance and evolution of rheological properties of high performance fiber reinforced cementitious composites with adapted rheology," in Rheology and Processing of Construction Materials, Dresden, Germany, 2019.

[21] V. Nerella, M. Näther, A. Iqbal, M. Butler and V. Mechtcherine, "Inline quantification of extrudability of cementitious materials for digital construction," Cement and Concrete Composites, vol. 95, no. 1, pp. 260-270, 2019.

[22] V. Mechtcherine and V. Nerella, "Fresh state requirements to 3D-printable cement-based materials," Construction Printing Technology, vol. 1, pp. 10-17, 2020.

[23] S. Jo, C. Park, J. Jeong, S. H. Lee and S. H. Kwon, "A Computational Approach to Estimating a Lubricating Layer in Concrete Pumping," Computers, Materials and Continua, vol. 27, pp. 189-210, 2012.

[24] S. Kwon, P. Kyong, J. Kim and P. Surendra, "State of the Art on Prediction of Concrete Pumping," International Journal of Concrete Structures and Materials, vol. 10, pp. $75-85,2016$.

[25] V. Nerella and V. Mechtcherine, "Virtual Sliding Pipe Rheometer for estimating pumpability of concrete," Construction and Building Materials, vol. 170, pp. 366$377,2018$.

[26] H. Kwon, C. K. Park, J. H. Jeong, S. D. Jo and S. H. Lee, "Prediction of Concrete Pumping : Part II - Analytical Prediction and Experimental Verification," $A C I$ Materials Journal, vol. 110, no. 6, pp. 657-668, 2013.

[27] D. Kaplan, F. De Larrard and T. Sedran, "Design of Concrete Pumping Circuit," $A C I$ Materials Journal , vol. 102, pp. 110-117, 2005.

[28] M. Choi, Y. Kim and S. Kwon, "Prediction on pipe flow of pumped concrete based on shear-induced particle migration," Cement and Concrete Research, vol. 52, pp. 216-224, 2013.

[29] J. Yammine, M. Chaouche, M. Guerinet, M. Moranville and N. Roussel, "From ordinary rhelogy concrete to self compacting concrete: A transition between frictional and hydrodynamic interactions," Cement and Concrete Research, vol. 38, pp. 890-896, 2008.

[30] A. Perrot, Y. Melinge, P. Estelle and C. Lanos, "Vibro-extrusion: a new forming process for cement-based materials," Advances in Cement Research, vol. 21, no. 3, pp. 125133, 2009.

[31] H. Ogura, V. Nerella and V. Mechtcherine, "Developing and testing of strain-hardening cement-based composites (SHCC) in the context of 3D-printing.," Materials, vol. 11, art. 1375, 2018. 
[32] P. Banfill, M. Teixeira and R. Craik, "Rheology and vibration of fresh concrete: Predicting the radius of action of poker vibrators from wave propagation," Cement and Concrete Research, vol. 41, no. 9, pp. 932-941, 2011.

[33] A. Perrot, D. Rangeard and Y. Mélinge, "Prediction of the ram extrusion force of cementbased materials," Applied Rheology, vol. 24, no. 5, art. 53320, 2014.

[34] M. S. Choi, J. K. Young and K. K. Jin, "Prediction of Concrete Pumping Using Various Rheological Models," International Journal of Concrete Structures and Materials, vol. 8, no. 4, pp. 269-278, 2014.

[35] Y. Zhan, J. Gong, Y. Huang, C. Shi, Z. Zuo and Y. Chen, "Numerical study on concrete pumping behavior via local flow simulation with discrete element method," Materials, vol. 12, no. 9, pp. 1-21, 2019.

[36] B. D. Rabideau, P. Moucheront, F. Bertrand, S. Rodts, N. Roussel, C. Lanos and P. Coussot, "The extrusion of a model yield stress fluid imaged by MRI velocimetry," Journal of Non-Newtonian Fluid Mechanics, vol. 165, pp. 394-408, 2010.

[37] P. de Souza Mendes, M. Naccache, P. Varges and F. Marchesini, "Flow of viscoplastic liquids through axisymmetric expansions-contractions," Journal of NonNewtonian Fluid Mechanics, vol. 142, pp. 207-217, 2007.

[38] P. Jay, A. Magnin and J. Piau, "Numerical simulation of viscoplastic fluid flows through an axisymmetric contraction," Journal of fluids engineering, vol. 124, pp. 700-705, 2002.

[39] S. Abdali, E. Mitsoulis and N. Markatos, "Entry and exit flows of Bingham fluids," Journal of Rheology, vol. 36, pp. 389-407, 1992.

[40] E. Mitsoulis, S. Abdali and N. Markatos, "Flow simulation of herschel-bulkley fluids through extrusion dies," The Canadian Journal of Chemical Engineering, vol. 71, pp. 147-160, 1993.

[41] A. Perrot, D. Rangeard, V. Nerella and V. Mechtcherine, "Extrusion of cement-based materials - an overview," RILEM Technical Letters, vol. 3, pp. 91-97, 2019.

[42] B. D. Rabideau, P. Moucheront, F. Bertrand, S. Rodts, Y. Mélinge, C. Lanos and P. Coussot, "Internal flow characteristics of a plastic kaolin suspension during extrusion," Journal of the American Ceramic Society, vol. 95, no. 2, pp. 494-501, 2012.

[43] H. Khelifi, A. Perrot, T. Lecompte, D. Rangeard and G. Ausias, "Prediction of extrusion load and liquid phase filtration during ram extrusion of high solid volume fraction pastes," Powder Technology, vol. 249, pp. 258-268, 2013.

[44] G. Grampeix, Vibration des bétons, Universite Paris-Est, 2013. 
[45] Y. Mélinge, V. Hoang, D. Rangeard, A. Perrot and C. Lanos, "Study of tribological behaviour of fresh mortar against a rigid plane wall," European Journal of Environmental and Civil Engineering, vol. 17, pp. 419-429, 2013.

[46] F.-X. Mortreuil, C. Lanos, C. Casandjian and M. Laquerbe, "Utilisation des propriétés électriques des pâtes céramiques pour leur extrusion," L'Industrie céramique \& verrière, pp. 88-95, 2000.

[47] S. Nair and R. Ferron, "Real time control of fresh cement paste stiffening: Smart cementbased materials via a magnetorheological approach," Rheologica Acta, vol. 55, pp. 571-579, 2016.

[48] F. Bos, R. Wolfs, Z. Ahmed and T. Salet, "Large Scale Testing of Digitally Fabricated Concrete (DFC) Elements," in First RILEM International Conference on Concrete and Digital Fabrication - Digital Concrete 2018. DC 2018. , 2018.

[49] A. Perrot, Y. Mélinge, D. Rangeard, F. Micaelli, P. Estellé and C. Lanos, "Use of ram extruder as a combined rheo-tribometer to study the behaviour of high yield stress fluids at low strain rate," Rheologica Acta, vol. 51, no. 8, pp. 743-754, 2012.

[50] W. Leal da Silva, H. Fryda, J.-N. Bousseau, P.-A. Andreani and T. Andersen, "Evaluation of Early-Age Concrete Structural Build-Up for 3D Concrete Printing by Oscillatory Rheometry," Advances in Additive Manufacturing, Modeling Systems and 3D Prototyping. AHFE 2019. Advances in Intelligent Systems and Computing, vol. 975, pp. 35-47, 2019.

[51] T. Wangler, F. Scotto, E. Lloret-Fritschi and R. Flatt, "Residence Time Distributions in Continuous Processing of Concrete.," in Rheology and Processing of Construction Materials. RheoCon 2019, SCC 2019. RILEM Bookseries, vol 23. , Dresden, Germany, 2020.

[52] H. Bessaies-Bey, R. Baumann, M. Schmitz, M. Radler and N. Roussel, "Organic admixtures and cement particles: Competitive adsorption and its macroscopic rheological consequences," Cement and Concrete Research, vol. 80, pp. 1-9, 2016.

[53] Espacenet, "Sika Technology (Mixer, system for applying a building material and method for producing a structure from building material)," Sika Tech AG, 31 July 2019. [Online]. Available: https://dk.espacenet.com/publicationDetails/biblio? II $=12 \& \mathrm{ND}=3 \&$ adjacent $=$ true \&locale $=$ dk_DK\&FT $=$ D\&date $=20190731 \& C C=Z A \& N R=201806381 B \& K C=B$. [Accessed 13 December 2019].

[54] Espacenet, "Baumit (Nozzle for concrete, mortar or Similar and its use)," Baumit Beteiligungen $\mathrm{GmbH}, 15$ January 2019. [Online]. Available: https://dk.espacenet.com/publicationDetails/biblio? II =1\&ND=3\&adjacent=true \&1 ocale $=\mathrm{dk} \_\mathrm{DK} \& \mathrm{FT}=\mathrm{D} \&$ date $=20190115 \& \mathrm{CC}=\mathrm{AT} \& \mathrm{NR}=520143 \mathrm{~A} 1 \& \mathrm{KC}=\mathrm{A} 1$. [Accessed 13 December 2019]. 
[55] N. Roussel and A. Gram, Simulation of Fresh Concrete Flow, Springer, 2014.

[56] N. Roussel, M. Geiker, F. Dufour, L. Thrane and P. Szabo, "Computational modeling of concrete flow: General overview," Cement and Concrete Research, vol. 37, no. 9, pp. 1298-1307, 2007.

[57] K. Krenzer, V. Mechtcherine and U. Palzer, "Simulating mixing processes of fresh concrete using the discrete element method (DEM) under consideration of water addition and changes in moisture distribution," Cement and Concrete Research, vol. 115, pp. 274-282, 2019.

[58] T. T. Le, S. A. Austin, S. Lim, R. A. Buswell, A. G. F. Gibb and T. Thorpe, "Mix design and fresh properties for high-performance printing concrete," Materials and Structures, vol. 45, pp. 1221-1232, 2012.

[59] S. Lim, R. Buswell, T. Le, S. Austin, A. Gibb and T. Thorpe, "Developments in construction-scale additive manufacturing processes," Automation in Construction, vol. 21, pp. 262-268, 2012.

[60] A. Suiker, R. Wolfs, S. Lucas and T. Salet, "Elastic buckling and plastic collapse during 3D concrete printing," Cement and Concrete Research, vol. Digital Concrete Special Issue, 2020.

[61] R. Wolfs, F. Bos and T. Salet, "Triaxial compression testing on ear-ly age concrete for numerical analysis of 3D concrete printing," Cement and Concrete Composites, vol. 104, art. 103344, 2019.

[62] F. Irgens, Continuum Mechanics, Berlin, Germany: Springer, 2008.

[63] T. Di Carlo, B. Khoshnevis and A. Carlson, "Experimental and numerical techniques to characterize structural properties of fresh concrete," Proceedings of the ASME 2013 International Mechanical Engineering Congress \& Exposition, 2013.

[64] A. S. J. Suiker, "Mechanical performance of wall structures in 3D printing processes: Theory, design tools and experiments," International Journal of Mechanical Sciences, vol. 137, pp. 145-170, 2018.

[65] S. Chaves Figueiredo, C. Romero Rodríguez, Z. Ahmed, D. Bos, Y. Xu, T. Salet, O. Çopuroğlu, E. Schlangen and F. Bos, "An approach to develop printable strain hardening cementitious composites," Materials \& Design, vol. 169, art. 107651, 2019.

[66] H. Jeong, S.-J. Han, S.-H. Choi, Y. Lee, S. Yi and K. Kim, "Rheological Property Criteria for Buildable 3D Printing Concrete," Materials, vol. 12, no. 4, art. 657, 2019.

[67] P. Kruger, S. Zeranka and G. van Zijl, "An ab initio approach for thixotropy characterisation of (nanoparticle-infused) 3D printable concrete," Construction and Building Materials, vol. 224, pp. 372-386, 2019. 
[68] S. Paul, Y. Tay, B. Panda and M. Tan, "Fresh and hardened properties of 3D printable cementitious materials for building and construction," Archives of Civil and Mechanical Engineering, vol. 18, no. 1, pp. 311-319, 2018.

[69] B. Panda and M. Tan, "Experimental study on mix proportion and fresh properties of fly ash based geo-polymer for 3D concrete printing," Ceramics International, vol. 44, no. 9, pp. 10258-10265, 2018.

[70] B. Zhu, J. Pan, B. Nematollahi, Z. Zhou, Y. Zhang and J. Sanjayan, "Development of 3D printable engineered cementitious composites with ultra-high tensile ductility for digital construction," Materials \& Design, vol. 181, art. 108088, 2019.

[71] R. Wolfs, F. Bos and T. Salet, "Correlation between destructive compression tests and non-destructive ultrasonic measurements on early age 3D printed concrete," Construction and Building Materials, vol. 181, pp. 447-454, 2018.

[72] Y. Zhang, Y. Zhang, G. Liu, Y. Yang, M. Wu and B. Pang, "Fresh properties of a novel 3D printing concrete ink," Construction and Building Materials, vol. 174, pp. 263$271,2018$.

[73] B. Panda, J. H. Lim and M. J. Tan, "Mechanical properties and deformation behaviour of early age concrete in the context of digital construction," Composites Part B, vol. 165 , pp. 563-571, 2019.

[74] F. Bos, R. Wolfs, Z. Ahmed, L. Hermens and T. Salet, "The influence of material temperature on the in-print strength and stability of a 3D print mortar," in Proceedings of the Seventh International Conference on Structural Engineering, Mechanics, and Computation (SEMC2019), Cape Town, South Africa, September 2019.

[75] R. Comminal, M. Serdeczny, D. Pedersen and J. Spangenberg, "Numerical Modeling of the Strand Deposition Flow in Extrusion-based Additive Manufacturing," Additive Manufacturing, vol. 20, pp. 68-76, 2018.

[76] E. Hovad, J. Spangenberg, P. Larsen, J. Thorborg and J. Hattel, "Simulating the DISAMATIC process using the Discrete Element Method - a dynamical study of granular flow," Powder Technology, vol. 303, pp. 228-240, 2016.

[77] V. Mechtcherine, A. Gram, K. Krenzer, J.-H. Schwabe, S. Shyshko and N. Roussel, "Simulation of fresh concrete flow using Discrete Element Method (DEM): theory and applications," Materials and Structures, vol. 47, no. 4, pp. 615-630, 2014.

[78] V. Nerella, M. Beigh, S. Fataei and V. Mechtcherine, "Strain-based approach for measuring structural build-up of cement pastes in the context of digital construction," Cement and Concrete Research, vol. 115, pp. 530-544, 2019.

[79] I. Ivanova and V. Mechtcherine, "Evaluation of Structural Build-Up Rate of Cementitious Materials by Means of Constant Shear Rate Test: Parameter Study," 
in Rheology and Processing of Construction Materials. RheoCon 2019, SCC 2019. RILEM Bookseries, vol 23., Dresden, Germany., 2019.

[80] I. Ivanova and V. Mechtcherine, "Possibilities and challenges of constant shear rate test for evaluation of structural build-up rate of cementitious materials," Cement and Concrete Research, vol. 130, art. 105974, 2020.

[81] N. Roussel, G. Ovarlez, S. Garrault and C. Brumaud, "The origins of thixotropy of fresh cement pastes," Cement and Concrete Research, vol. 42, pp. 148-157, 2012.

[82] N. Roussel, "A thixotropy model for fresh fluid concretes: theory, validation and applications," Cement and Concrete Research, vol. 36, no. 10, pp. 1797-1806, 2006.

[83] N. Roussel, "Steady and transient flow behaviour of fresh cement pastes," Cement and Concrete Research, vol. 35, no. 9, pp. 1656-1664, 2005.

[84] K. V. Subramaniam and X. Wang, "An investigation of microstructure evolution in cement paste through setting using ultrasonic and rheological measurements," Cement and Concrete Research, vol. 40, no. 1, pp. 33-44, 2010.

[85] A. Perrot, A. Pierre, S. Vitaloni and V. Picandet, "Prediction of lateral form pressure exerted by concrete at low casting rates," Materials and Structures, vol. 48, no. 7, pp. 1-8, 2014.

[86] T. Lecompte and A. Perrot, "Non-Linear modelling of yield stress increase due to SCC structural build-up at rest," Cement and Concrete Research, vol. 92, pp. 92-97, 2017.

[87] S. Mantellato, M. Palacios and R. Flatt, "Relating early hydration, specific surface and flow loss of cement pastes," Material and Structures, vol. 52, art. 5, 2019.

[88] M. Rubio, M. Sonebi and S. Amziane, "3D printing of fibre cement-based materials: fresh and rheological performances," Proceedings of 2nd ICBBM (PRO 119), pp. 284-291, 21-23 June 2017. 